\title{
Die diagnostische Bedeutung der Bestimmung von Harnenzymaktivitäten
}

\author{
Von W. RAAB \\ Aus dem Institut für Medizinische Chemie der Universität Wien (Vorstand Prof. Dr. F. Seelich)
}

(Eingegangen am 11. Mai 1970)

\begin{abstract}
Die vorliegende Ưbersicht beschäftigt sich nach einem Uberblick über die Herkunft und Physiologie der Harnenzymaktivitäten beim Menschen mit den unter verschiedenen pathologischen Bedingungen auftretenden Veränderungen. Besonderes Augenmerk wurde bei der Besprechung der einzelnen Aktivitäten der Frage zugewendet, inwieweit hier Untersuchungsergebnisse von diagnostischem Wert sind. Dic Kenntnisse der hier zusammengestellten Tatsachen könnte dem Klinischen Chemiker zahlreiche Anregungen vermitteln, da in vieler Hinsicht die Enzymdiagnostik des Harnes heute noch in den Anfängen steckt. Die vereinzelt nicht allzu leicht interpretierbaren Ergebnisse größeret Untersuchungsreihen sollten für weitere Untersuchungen unter modifizierten Bedingungen als Anreiz dienen. Abschließend wird noch kurz die Bedeutung enzymatischer Untersuchungen des Harnes in der experimentellen Pharmakologie betont.
\end{abstract}

\section{The diagnostic value of urinary enzyme determinations}

Following an account of the origin and physiology of the human urinary enzyme activities, the changes that occur under different pathological conditions are discussed. In dealing with each enzyme activity, particular attention is paid to the question of whether its measurement has any diagnostic value. A knowledge of the facts collected together here could act as a stimulus to further work on the use of urinary enzymes for diagnosis, a subject that in many respects is still in its infancy. If the results of a long, isolated series of investigations are difficult to interpret, the conditions should be modified and further studies undertaken.

Finally, the importance of the study of urinary enzymes in experimental pharmacology is briefly stressed.

Die Einführung moderner enzymatischer Bestimmungsmethoden in der klinischen Chemie brachte bedeutende Verbesserungen der diagnostischen Möglichkeiten und eröffnete ein weites Feld für neue Untersuchungen. Bei einer großen Zahl wichtiger Erkrankungen ist heute die Bestimmung von Enzymaktivitäten im Serum aus der Diagnostik und Verlaufsbeurteilung nicht mehr wegzudenken. Außer im Serum gibt es Enzymaktivitäten noch in vielen anderen Körperflüssigkeiten, so auch im Harn. Obzwar das Vorkommen von Harnenzymen schon über 150 Jahre bekannt ist, wurden erst im letzten Jahrzehnt breitere Untersuchungen über die Veränderungen der Harnenzymaktivitäten unter verschiedensten klinischen und experimentellen Bedingungen vorgenommen. Insbesondere interessierte immer wieder die Frage, ob durch Bestimmung der Enzymausscheidung im Harn die medizinische Diagnostik ganz allgemein und die urologische Diagnostik im besonderen eine Erweiterung erfahren könnten.

Utber die diagnostische Anwendbarkeit der Enzymbestimmungen im Harn liegen widersprüchliche Aussagen vor; die Leistungsfähigkeit dieser Methoden ist vielfach noch unklar. Bisher fehlt auch noch eine systematische Zusammenstellung der doch schon recht zahlreichen Einzelmitteilungen zu diesem Fragengebiet. Im folgenden soll deshalb versucht werden, die Veränderungen der Harnenzymaktivitäten unter verschiedenen pathologischen Bedingungen kritisch zusammenzustellen und dem klinischen Chemiker ebenso wie dem Internisten und Urologen die Möglichkeiten zur diagnostischen Verwertung solcher Untersuchungsergebnisse aufzuzeigen.

\section{Herkunft der Enzymaktivitäten im Harn}

Zum besseren Verständnis der pathologischen Enzymurien soll zunächst einmal die Physiologie der Enzymausscheidung im Harn besprochen werden. Unter normalen Bedingungen stammen die Enzymaktivitäten des Harns aus folgenden vier Quellen:

\section{Aus dem Serum:}

Durch glomeruläre Filtration kleinmolekularer Proteine - als oberste Grenze wird ein Molekulargewicht von 80000 angenommen - gelangen Enzymaktivitäten aus dem Serum in den Harn. Hierbei ist allerdings $\mathrm{zu}$ berücksichtigen, daß als Folge einer tubulären Rückresorption viele kleinmolekulare Proteine zwar im Primärharn, nicht aber im Harn erscheinen. Experimentell konnte beim Menschen gezeigt werden, $\mathrm{daB}$ - wie auch nach dem oben Gesagten zu erwarten war - die intravenöse Verabreichung großmolekularer Enzyme (Glutamatdehydrogenase EC 1.4.1.2) zu keinem Auftreten einer entsprechenden Aktivität im Harn führt $\left.(7)^{1}\right)$. Andererseits erscheint auch die kleinmolekulare Urokinase nach intravenöser Verabreichung nicht im Harn, sondern wird über die Galle ausgeschieden.

\section{Aus der Niere:}

Die Tubulusepithelien der Niere sind außerordentlich reich an verschiedenen Enzymaktivitäten. Im Rahmen des normalen Turnover werden laufend Zellen abge-

1) Literaturverzeichnis ausnahmsweise in alphabetischer Reihenfolge. 
stoßen und desintegricren. Enzyme dieser Epithelien erscheinen im Harn; allerdings sind nicht alle Enzyme im Harn auch tatsächlich nachweisbar. Weiter gelangen auch als Folge der Permeation in den Nierenkanälchen Enzyme aus den lumennahen, besonders enzymreichen Anteilen dcr Tubuluszellen (Bürstensäume) in die tubuläre Flüssigkeit und in weiterer Folge in den Harn.

\section{Aus Epithelzellen der ableitenden Harnwege:}

Im Rahmen des normalen Turnover desquamieren laufend Epithelzellen der ableitenden Harnwege - ebenso wie in der Niere - und die Enzyme der zerfallenden Zellen können im Harn erscheinen. Da der Enzymgehalt dieser Zellen im Vergleich zu den Tubulusepithelien der Niere meist nur sehr gering ist, kommt dieser Quelle von Harnenzymaktivitäten nur eine untergeordnete Bedeutung zu.

\section{Aus Drüsen des Urogenitaltraktes:}

Drüsensekrete der Urogenitaldrüsen sind zum Teil reich an Enzymen. Diese Sekrete sind oft dem Harn beigemischt und ihre Enzyme lassen sich im Harn nachweisen. Von wesentlicher Bedeutung ist diese Quelle von Harnenzymaktivitäten im Falle der sauren Phosphatase (EC 3.1.3.2) aus der Prostata (deutlicher Aktivitätsunterschied bei Mann und Frau, bzw. bei männlichen und weiblichen Versuchstieren) (153), sowie der $\beta$-Glucuronidase (EC 3.2.1.31) aus den Präputialdrüsen (31) und der Aminotransferasen aus dem Sperma (140, 200).

Unter pathologischen Bedingungen kann entweder eine Veränderung an den oben genannten vier Herkunftsstellen der Harnenzyme erfolgen, was entweder $\mathrm{zu}$ einer Steigerung oder $\mathrm{zu}$ einem Absinken von Harnenzymaktivitäten führt, oder es gelangen Enzyme von weiteren Quellen in den Harn. Unter pathologisiben Bedingungen können Harnenzymaktivitäten aus folgenden Körperflüssigkeiten oder Strukturen stammen:

\section{Aus dem Serum:}

Bei pathologisch gesteigerter Permeabilität in den Glomerula oder bei gestörter tubulärer Rückresorption treten neue Enzymaktivitäten im Harn auf, bzw. es läßt sich eine Steigerung normaler Aktivitäten feststellen. Im Bezug auf die Störung der glomerulären Filtration ist $z u$ berücksichtigen, daß häufig eine selektive Erhöhung der Permeabilität eintritt (29) und daß deshalb nicht alle Enzyme in gleicher Weise in den Primärharn übertreten. Eine Störung der tubulären Rückresorption kann sowohl toxisch als auch hypoxisch (Schocknicre) bedingt sein. Wie später noch auszuführen sein wird, ist das Enzymspektrum des Harnes bei Proteinurie besonders reich $(18,93)$.

\section{Aus der Niere:}

Beim Zugrundegehen zahlreicher Nierenepithelien und bei massiven Permeabilitätsstörungen erfolgt eine Steigerung der renalen Enzymurie oder sogar das Neu- auftreten bestimmter, aus der Niere stammender Enzyme im Harn. Bei toxischen Schädigungen der Tubuluszollen wird die renale Enzymausscheidung in ihrer Art und Intensität durch mehrere Faktoren beeinflußt. In Tabclle 1 (modifiziert nach 1. c. (140)) sind die wichtigsten dieser Faktoren zusammengestellt. Für experimentelle Untersuchungen dieser Verhältnisse hat sich die Ratte besonders bewährt, da dieses Tier in der Niere ein weitgehend ähnliches Enzymmuster aufweist wie der Mensch (43). Theoretisch wäre zu fordern, daß

Tab. 1

Determinierende Faktoren für die renale Enzymausscheidung be Tubulusschädigung

1. Intensität der Noxe

2. Enzymmuster im betroffenen Abschnitt

3. Lokalisation der Enzyme innerhalb der geschädigten Zelle

4. Strukturbindung der Enzyme

5. Physikalisch-chemische Eigenschaften der Enzymproteine wie Größe, Form usw.

ein massives Zugrundegehen von Tubuluszellen zum Auftreten aller hierbei freiwerdenden Enzyme im Harn führt (vgl. 1. c. (131)), aber praktisch - wahrscheinlich aus Gründen der Stabilität - ist dies nicht der Fall. So konnte z. B. nach massiver Nierenschädigung keine Succinatdehydrogenase-Aktivität (EC 1.3.99.1) im Rattenharn nachgewiesen werden, obzwar aufgrund histochemischer Untersuchungen im gleichen Experiment die Verarmung der Niere an diesem Enzym sichergestellt werden konnte (158).

\section{Aus Tumoren:}

Durch Zerfall von Tumoren der Epithelien der ableitenden Harnwege, der Urogenitaldrüsen und der Genitalorgane gelangen Enzyme der Tumorzellen in den Harn.

\section{Aus Infiltrat-und Exsudatzellen:}

Bei Entzündungen im Bereich der Niere und der ableitenden Harnwege oder des Urogenitaltraktes wandern verschiedene enzymreiche Zellen ein (Leukocyten, Lymphocyten). Wenn diese Zellen zerfallen, erscheinen ihre Enzyme sehr häufig im Harn (Nachweis z. B. durch Bestimmung von Isoenzymen).

\section{Aus Erythrocyten:}

Bei Blutungen im Bereich der Niere, der ableitenden Harnwege oder der Genitalorgane gelangen Erythrocyten in den Harn. Durch Zerfall werden ihre Enzyme frei. Die gleiche Aussage gilt für Erythrocyten, die bei schweren Nephritiden durch die Glomerula in das hambereitende System gelangen.

\section{Aus Bakterien:}

Bei bakteriellen Entzündungen der Niere (Pyelonephritis, Nierenabszesse) oder anderer Anteile des Urogenitaltraktes gelangen Bakterien in den Harn. Durch Zerfall erscheinen die Enzyme der Bakterien im 


\section{ARBEITSMETHODEN}

DER MODERNEN NATURWISSENSCHAFTEN

Herausgegeben von Prof. Dr. KuRt FisChBeCK

\section{KONRAD DORFNer}

\section{Ionenaustauscher}

\section{Auflage}

Mit 100 Abbildungen, 27 Tabellen im Text und 1 Tabellenanhang (mit 19 Tabellen) Oktav. XII, 320 Seiten. 1970. Plastikeinband DM 58,-

Nach der erweiterten Einführung wird cine ausführlichere Darstellung der verschicdenen Ionenaustauschertypen sowic ihrer Eigenschaften und Prüfmethoden gegeben. Besonders über die Verwendung der Ionenaustauscher in der Technik wird im einzelnen berichtet, um den Neuentwicklungen gerecht zu werden. So sind die rechnerische Behandlung und die speziellen Verfahren des Festbettverfahrens, die neuesten Entwicklungen der kontinuierlichen Verfahren, die Wasseraufbereitung mit Ionenaustauschern und die Verwendung der Ionenaustauscher zur Abwasserreinigung, Metallgewinnung, Zuckerherstellung und sonstiger technischer $\Lambda$ nwendungen in dem vorgegebenen Rahmen so umfassend wie möglich dargestellt worden. Die übrigen Kapitel wurden nach den neuesten Ergebnissen durchgearbeitet, verbessert und crgänzt.

JohanNes FlügGe

\section{Grundlagen der Polarimetrie}

Gerätekunde und Meßtechnik

Oktav. Mit 72 Abbildungen und 28 Tabellen. XII, 159 Seiten. 1970. Plastikeinband DM 48,-

Wurde die Polarimetrie bereits seit langem als analytisches Verfahren, z. B. in Zuckerfabriken und in Betrieben der pharmazeutischen Chemie, angewandt, so hat sie sich in neuerer Zeit auch in der Erforschung von Molekülstrukturen als aufschlußreich etwiesen, besonders seitdem es automatische und Spektralpolarimeter bis ins Ultraviolett gibt. Das vorliegende Werk informiert über Grundlagen, Meßtechnik und moderne Geräte dieser optischen Methode und berücksichtigt ihren Stand bis in die jüngste Zeit, wobei neben der Analytik auch die Bestimmung der Rotationsdispersion, der magneto-optischen Drehung des Lichts und der Elliptizität, wie sie boi Zirkulardichroismus auftritt, besprochen werden. Photoelektrische Polarimeter und Saccharimeter werden ausführlich behandelt.

Walter de Gruyter • Berlin • New York

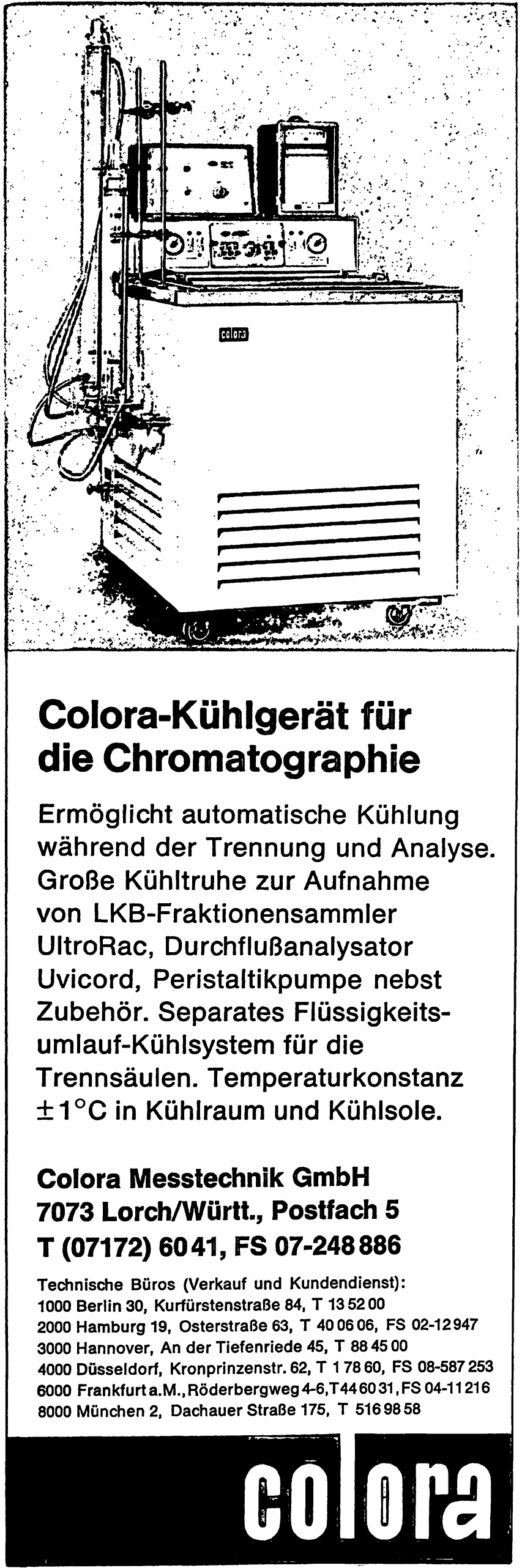




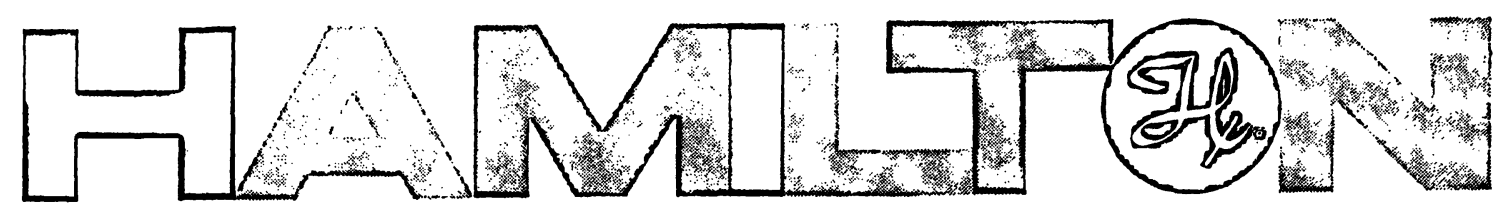

Reproduzierbare Präzision: Hamilton 5-500 Mikroliter Spritzen

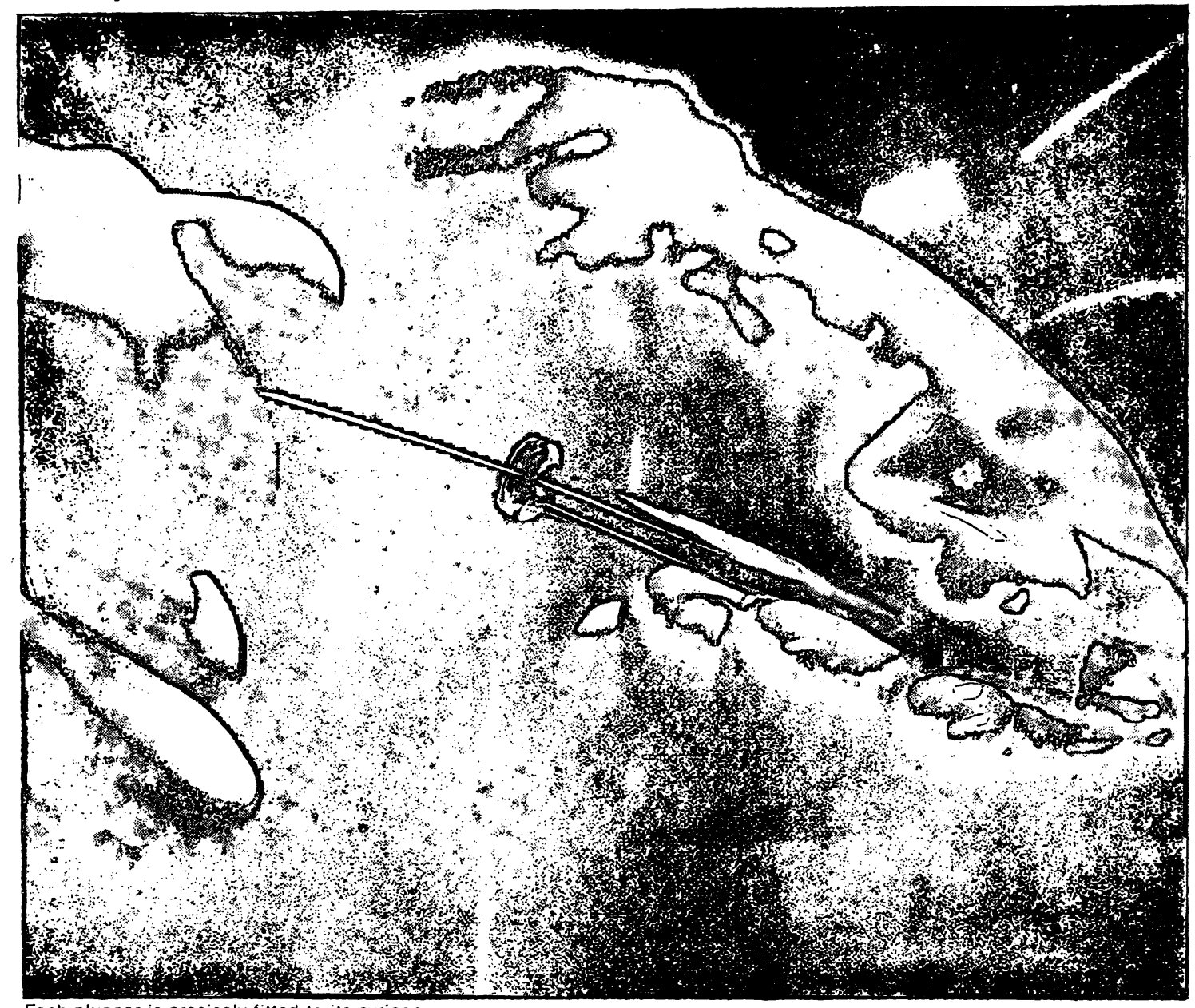

Each plunger is precisely fitted to its syringe.

\section{Präzision bedarf der helfenden Hand}

wenn Sie erwarten, dass Probe für Probe ein Ergebnis mit reproduzierbarer Genauigkeit haben soll. Darum - nach dem Einsatz hochwertiger Präzisionsmaschinen für unsere Materialbearbeitung - setzen wir in Handarbeit unsere Spritzen zusammen, passen die Kolben ein und prüfen die Spritzen nochmals. Wir arbeiten mit grösster Präzision; weil es um die Qualität Ihrer Spritzen geht. Die Spritzentype 700 garantiert eine reproduzierbare Probenabgabe bei $\pm 1 \%$. Deshalb wurde die HAMILTON-Mikroliterspritze als Standard-Messinstrument in den Laboratorien der ganzen Welt bekannt.

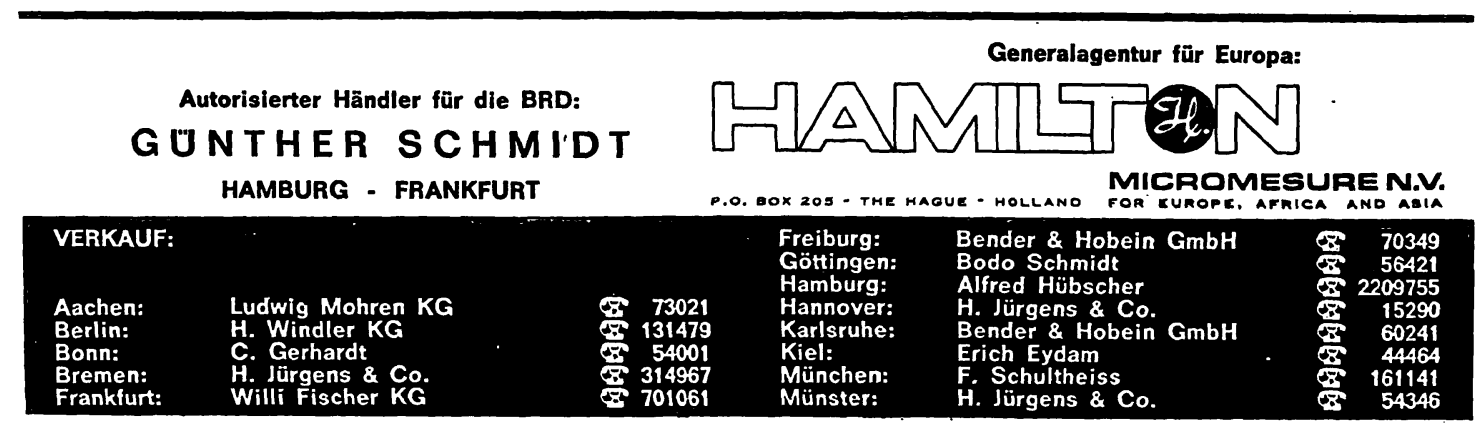


Harn. In erster Linie ist hier die Katalase (EC 1.11.1.6) anzuführen.

Bei Überlegung der verschiedenen Herkunftsmöglichkeiten von Harnenzymen unter pathologischen Bedingungen ergibt sich die Schlußfolgerung, daß praktisch alle schwereren Veränderungen im Bereich der Niere zu Veränderungen von Harnenzymaktivitäten führen müssen. Eine Spezifität der Diagnostik erscheint also bereits von den physiopathologischen Grundlagen her eher $z$ weifelhaft.

\section{Aktivatoren und Inhibitoren}

Über das Auftreten von Aktivatoren und Inhibitoren verschiedener Enzymaktivitäten im Harn ist außer der Tatsache als solcher noch nicht viel bekannt. Am längsten bekannt ist das Vorkommen eines Trypsininhibitors im Harn (55). Ferner lassen sich in Harnen des Menschen und verschiedener Versuchstiere auch Hemmstoffe der Lactatdehydrogenase (EC 1.1.1.27) und der alkalischen Phosphatase (EC 3.1.3.1) nachweisen $(140,186)$. Weitere Angaben und Zusammenstellung über Enzyminhibitoren und Aktivatoren im Harn wurden an anderer Stelle publiziert (140). In vielen Fällen genügt eine Dialyṣe des Harnes durch mehrere Stunden (198) - den eigenen Erfahrungen nach am besten durch drei Stunden gegen fließendes Leitungswasser - um derartige störende Inhibitoren zu entfernen. Es spricht vieles dafür, daß unter pathologischen Veränderungen auch eine Verschiebung in der Harnausscheidung von Enzyminhibitoren und -aktivatoren eintritt. Entsprechende Untersuchungen könnten wesentlich zur Beurteilung der unter pathologischen Bedingungen eintretenden Veränderungen von Harnenzymaktivitäten beitragen und möglicherweise sogar von diagnostischer Bedeutung sein.

An dieser Stelle sei darauf verwiesen, daß im Harn ausgeschiedene Arzneimittel oder Arzneimittelmetaboliten mit der Bestimmung von Harnenzymaktivitäten interferieren können. Bei klinisch-pharmakologischen Untersuchungen muß vor Beurteilung der gemessenen Veränderungen der Harnenzymaktivitäten ein derartiger Mechanismus durch in-vitro-Experimente ausgeschlossen werden. Bisher wurde z. B. eine Störung von Enzymbestimmungen durch Nitrofurantoin (123) und Ethionamid (eigene unveröffentlichte Befunde) beobachtet. Ferner ist zu berücksichtigen, daß Medikamente mit Einfluß auf die Fibrinolyse die Aktivität von Aminpeptidasen im Harn verändern (siehe später). Derartige direkte Einflüsse von Arzneimittel können also neben einem nephrotoxischen Effekt und neben der Steigerung tubulärer Sekretionsprozesse (funktionelle Enzymurie?) zu Veränderungen bestimmter Harnenzymaktivitäten führen.

\section{Übersicht über die Enzymaktivitäten im Harn}

In Harnen des Menschen und verschiedener Versuchstiere konnten bereits eine große Zahl von Enzymaktivitäten nachgewiesen werden; viele dịeser. Enzym-
Tab. 2

Harnenzyme bei Mensch und Tier

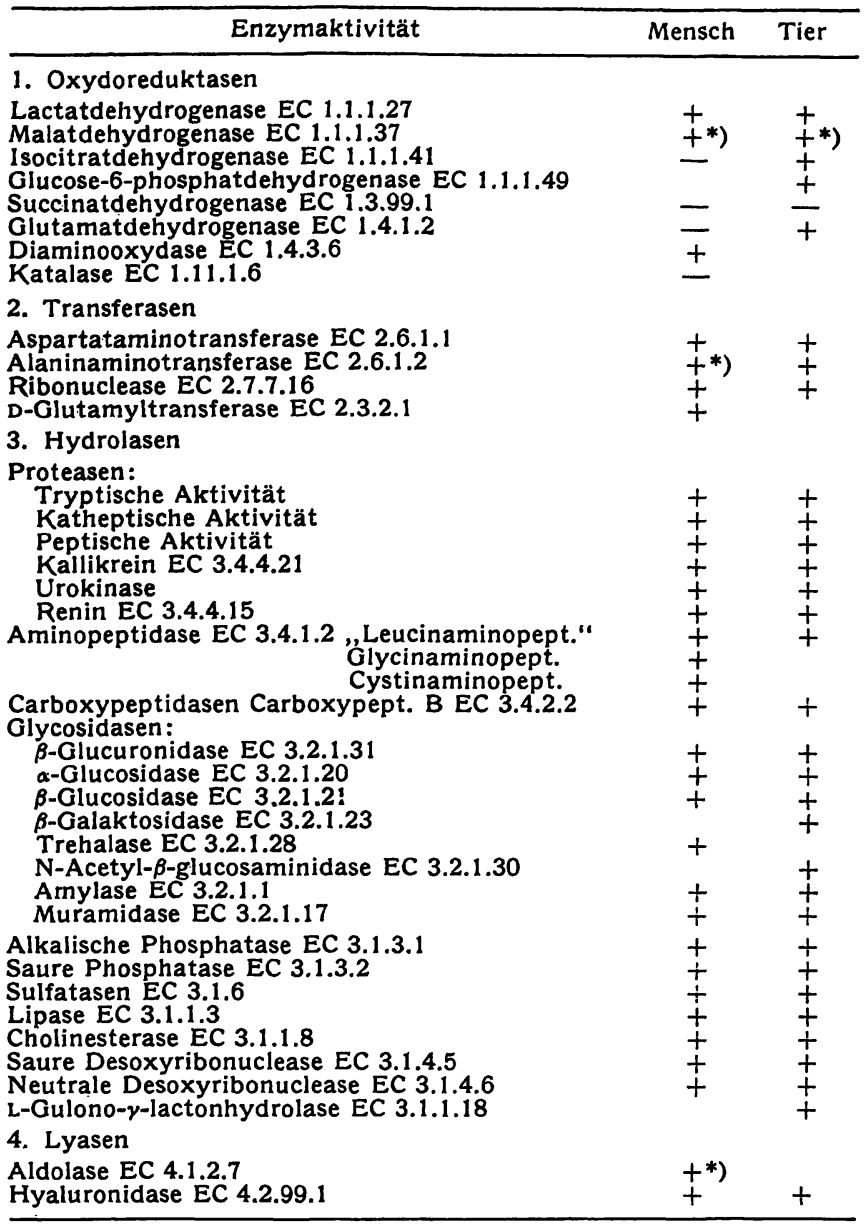

*) Nur in pathologischen Harnen!

aktivitäten ließen sich in Isoenzyme auftrennen (Beispiele: Lactatdehydrogenase (EC 1.1.1.27), Amylase (EC 3.2.1.1), Phosphatasen (EC 3.1.3)). Nach der biochemischen Klassifizierung gehören die bisher nachgewiesenen Harnenzyme zu den Oxydoreduktasen, Transferasen, Hydrolasen oder Lyasen. In Tabelle 2 sind alle bisher im Harn beschriebenen Enzymaktivitäten zusammengestellt.

Von der großen Zahl der in menschlichen Harnen nachgewiesenen Enzymaktivitäten erlangten nur wenige wirkliche Bedeutung: von den aus dem Serum stammenden Harnenzymen das Uropepsinogen und die Amylase (EC 3.2.1.1), von den aus der Niere stammenden Harnenzymen die Lactatdehydrogenase (EC 1.1.1.27), die alkalische Phosphatase (EC 3.1.3.1), die „Leucinaminopeptidase“ (EC 3.4.1.1) und die Glucuronidase (EC 3.2.1.31). Diese Enzyme sollen entsprechend der größeren Zahl von Angaben über ihr Verhalten unter physiologischen und pathologischen Bedingungen ausführlicher besprochen werden.

\section{Berechnung der Harnenzymaktivitäten}

Angaben über Harnenzymaktivitäten pro $\mathrm{m} l$ Harn erscheinen in den meisten Fällen wertlos. In Perioden von Diurese und Antidiurese variieren diese Werte infolge der verschiedenen Durchspülung der Tubuluskanälchen und der funktionell geänderten Permeabilität der 
Nierenkanälchen sehr stark, besonders bei Betrachtung von Harnenzymen renalen Ursprungs (85). Am besten bewährte sich die Bestimmung der Gesamtạusscheidung über 24 Stdn., nur stehen derartig langen Harnsammelperioden häufig technische Schwierigkeiten entgegen, zumindest bei Untersuchungen am Menschen. Als minimale Harnsammelperiode wird ein Zeitraum von $8 \mathrm{Stdn}$. angegeben und die Angaben über Harnenzymaktivitäten im Sammelharn können sich auf den gesamten Zeitraum beziehen. Die Harnsammlung über Nacht kann unter Umständen zu fehlerhaften Ergebnissen führen - abgesehen von der Möglichkeit der tagesrhythmischen Schwankungen - da bei Herz- und Kreislaufschwäche über Nacht wesentlich mehr Enzymaktivität ausgeschieden wird als tagsüber (79). Um konstantere Werte zu erzielen, wurde auch versucht, die Harnenzymausscheidung mit der Kreatininausscheidung in Beziehung zu setzen.

\section{Diurese und Ionenausscheidung}

Durch Auslösung einer Wasserdiurese im akuten Versuch läßt sich eine Steigerung der renalen Enzymurie erzielen (80), bei Untersuchung längerer Zeiträume gleichen sich diese Veränderungen jedoch wieder aus. Die Verabreichung von Substanzen mit Einfluß auf die Diurese (Coffein (150) oder Vasopressin, bzw. Vasopressin-Oxytocin (146)) bewirkte im Tierversuch einen deutlichen Anstieg der renalen Enzymurie (24 Stdn.Versuch). Es ist jedoch anzunehmen, daß dieser Effekt nicht nur auf die unter der Einwirkung der genannten Substanzen veränderten Diuresebedingungen zurückgeht, zumindest nicht in direkter Weise.

In Anbetracht der engen Zusammenhänge zwischen Elektrolytstoffwechsel und tubulärer Permeabilität wurden bei Mensch und Tier die Auswirkung einer $\mathrm{Na}$ trium- und Kaliumbelastung sowie einer Natrium- und Kaliumverarmung (nur beim Tier) auf die renale Enzymausscheidung untersucht. Es war hierbei festzustellen, da $\beta$ selbst eine längerdauernde Belastung mit Natrium- oder Kaliumionen zu keinen Veränderungen der Harnenzymaktivitäten führt, ebensowenig wie längerdauernde Perioden einer Wasserdiurese (157). Eine Kaliumkarenz über längere Zeit verursachte jedoch bei der Ratte als Folge der bekannten hypokaliämischen Nephropathie $(119,164)$ einen deutlichen Anstieg der renalen Enzymurie; von Bedeutung erscheint der Befund, daß die massiven biochemischen Veränderungen im Harn lange vor dem Auftreten morphologisch faßbarer Veränderungen in der Niere festzustellen waren $(155,157)$. Eine Verarmung des Organismus an Natrium bewirkte bei Ratten ebenfalls einen Anstieg der renalen Enzymausscheidung, wobei für diesen Befund heute noch keine Erklärung gegeben werden kann (157).

Am Rande sei hier nur kurz die Vermutung berichtet, $\mathrm{daB}$ die Hyaluronidase-Aktivität des Harnes in Beziehung zur Diurese steht (Beeinflussung der Kittsubstanz in den Nierenkanälchen $(35,36)$.

\section{Harnenzymaktivitäten und intestinale Sekretion}

1. Uropepsinogen (Proteolyse bei pH 2,0-2,2):

Die Pepsinogenausscheidung im Harn hängt vom Serumpepsinogen $\mathrm{ab}$, welches wieder in direkter Beziehung zur Pepsinogensekretion der Magendrüsen steht. Durch Bestimmang des Uropepsinogens läßt sich in einer für den Patienten nicht belastenden Weise ein Anhaltspunkt für die sekretorische Magenfunktion gewinnen. Die relativ hohe Varianz der Normalwerte verlangt eine exakte Bestimmung, die technisch nicht ganz einfach ist (89). Der Wert der Uropepsinogenbestimmung ist umstritten: nach Ansicht einiger Autoren (33) bedeutet sie eine wertvolle Hilfe in der inneren Diagnostik, nach Ansicht anderer Autoren (20) kommt ihr nur geringe Bedeutung zu.

In der experimentellen Medizin bewährten sich Untersuchungen der Uropepsinogenausscheidung zur Beurteilung der Freisetzung von H-Substanzen (Histamin) und zur Feststellung des Einflusses verschiedener Pharmaka auf diesen Prozeß $(140,161)$.

Bei Störung der exkretorischen Nierenfunktion steigen die Serumaktivitäten der durch die Niere ausgeschiedenen Enzyme (wie Pepsinogen) an.

\section{Urokathepsin (Proteolyse bei pH 3,5-5,0):}

Die Bestimmung des Urokathepsins wurde in gleicher Weise wie die Bestimmung des Uropepsinogens als Funktionsprüfung für die Sekretion bestimmter Magendrüsen vorgeschlagen (10). $\mathrm{Da}$ aber die katheptische Aktivität des Harnes auch von den Zellkathepsinen der Niere abhängig ist, ergaben sich hinsichtlich der Funktionsprüfung der Magendrüsen weit weniger verläßliche Resultate als bei Bestimmung des Uropepsinogens. Die Untersuchung der katheptischen Aktivität des Harnes ist heute praktisch verlassen (71). Auch vom Tierexperiment her läßt sich die Bestimmung der Urokathepsine nicht empfehlen; die in verschiedenen Modelliversuchen gewonnenen Ergebnisse erwiesen sich als uneinheitlich und zeigten große Streuungen (161).

\section{Amylase (EC 3.2.1.1):}

Die Amylase-Aktivität des Harnes steht in direkter Beziehung zur Amylase des Serums. Im menschlichen Harn ließen sich 8 Isoamylasen aus 5 verschiedenen Quellen identifizieren: Pankreas, Speicheldrüsen, Dünndarm, laktierende Mamma und MüLLERsche Epithelien (78). Die wichtigste Quelle ist zweifellos das Pankreas. Allgemein wird die Ansicht vertreten, daß zur Diagnostik und Verlaufskontrolle von Pankreaserkrankungen Bestimmungen der Harnamylase wertvoller sind als Bestimmungen der Serumamylase $(62,74,65,92,114)$. Wegen der großen Streuungen der Normalwerte ist aber in der Interpretation der Befunde eine gewisse Vorsicht geboten. - Am Rande sei hier nur kurz erwähnt, daß bei akuter Hepatitis über eine erhöhte Aus- 
scheidung der Isoamylasen in der $\beta$-Globulinzone berichtet wurde (57).

\section{Harnesterase (EC 3.1.1.1):}

Vor kurzem erst wurde über eine Harnesterase (Substrat $\beta$-Naphthyllaurat) berichtet, die bei entzündlichen Erkrankungen des Darmes regelmäßig eine starke Steigerung erfährt; dieser Aktivitätsanstieg wurde auf die Ausschüttung eines Aktivators aus der Gallenblasen- und Darmwand zurückgeführt (51).

\section{Proteinurie}

Bei Proteinurie verschiedenster Ursache (Proteine aus dem Serum bei gestörter glomerulärer Filtration, Proteine aus der Niere bei massiver Nierenschädigung) steigen zahlreiche Harnenzymaktivitäten an, bzw. es kommt zum Neuauftreten einiger im Normalharn nicht nachweisbarer Enzyme wie Malatdehydrogenase (EC 1.1.1.37), Aspartataminotransferase (EC 2.6.1.1) (in manchen Normalharnen vorhanden) Alaninaminotransferase (EC 2.6.1.2) und Aldolase (EC 4.1.2.7) (77, 93, 182). Weiter wurde über erhöhte Aktivitäten von Lactatdehydrogenase (EC 1.1.1.27), alkalischer Phosphatase (EC 3.1.3.1), Leucinaminopeptidase (3.4.1.1) und $\beta$-Glucuronidase (EC 3.2.1.31) im Harn berichtet (Übersicht bei l. c. (140), vgl. die Abschnitte über die betreffenden Enzyme).

Bei toxischer Nierenschädigung nach Art einer Nephrose ließ sich bei der Ratte eine Erhöhung der Cholinesterase-(EC 3.1.1.8) (142), der Isocitratdehydrogenase-(EC 1.1.1.41) (149) und der Glutamatdehydrogenase-(EC 1.4.1.2) (147) Aktivität im Harn nachweisen.

\section{Katalase (EC 1.11.1.6)}

Unter normalen Bedingungen stammt die Katalase des menschlichen Harnes ausschließlich aus den Nierenzellen; in manchen menschlichen Harnen ist aie Katalase-Aktivität so gering, daß sie mit den üblichen Methoden nicht mehr erfaßt werden kann. Eine Erhöhung der Katalase-Aktivität im Harn kann durch eine Schädigung von Nierenzellen bedingt sein (117), da die Katalase der zugrundegehenden Zellen in den Harn gelangt. Unter pathologischen Bedingungen sind als zweite Quelle für Katalase im Harn Bakterien anzuführen; infizierte Harne zeigen sehr hohe KatalaseAktivitäten (24). Untersuchungen der Katalase-Aktivität im Harn wurden aus diesem Grund zur Frühdiagnose von Infektionen im Bereich der Niere und der ableitenden Harnwege empfohlen (84). Bei der Hochdruckniere kann die Erhöhung der Katalase-Aktivität im Harn entweder auf eine beginnende bakterielle Infektion (171) oder auf eine Gewebsschädigung zurückgehen.

\section{Muramidase (Lysozym) (EC 3.2.1.17)}

Die Muramidase-Aktivität des normalen menschlichen Harnes ist meist nur sehr gering; in manchen Harnen fehlt sie überhaupt. Bei Nierenerkrankungen tritt nach manchen Autoren $(25 ; 34,133)$ häufig, nach anderen
Autoren nur selten (7\% der Fälle) (68) eine Erhöhung der Muramidase-Aktivität im Harn ein. Dies kann auf einer verminderten tubulären Rückresorption des Serumenzyms beruhen ebenso wie auch auf dem Erscheinen renaler Muramidase im Harn. Betont wurde der Anstieg der Muramidase-Aktivität im Harn („Lysozymurie") bei nephrotischen Prozessen im Kindesalter (195) und bei Vorliegen einer chronischen Cadmium-Nephropathie (72). Die beginnende (drohende?) Abstoßung einer transplantierten Niere ist von einer Erhöhung der Muramidase-Aktivität des Harnes (neben zahlreichen anderen Enzymen) begleitet $(122,205)$. Bei Mastocytose sollen Beziehungen zwischen der Muramidase-Aktivität des Harnes und der Aktivität des Mukopolysaccharidstoffwechsels bestehen (172).

\section{Aminotransferasen (EC 2.6.1)}

Im normalen menschlichen Harn liegt in der Regel keine Alanin-Aminotransferase-Aktivität und keine (oder nur eine geringe) Aspartat-AminotransferaseAktivität vor. Infektionen des Urogenitaltraktes (24) sind ebenso wie tubuläre Schäden $(105,106,128,169$, 182) von einem Auftreten, bzw. einem Anstieg der Aspartattransaminase-Aktivität des Harnes begleitet; nur seltener findet sich unter solchen Bedingungen das Erscheinen einer Alanintransaminase-Aktivität (182). Dieses Verhalten wird durch die Ergebnisse des Tierversuchs bestätigt: bei tubulärer Schädigung (toxische Nephrose) steigt die Aspartattransaminase-Aktivität des Rattenharnes stark und die AlanintransaminaseAktivität gering an; eine hypoxische Nierenschädigung (vaskulärer Schock) bewirkt nur einen geringen Anstieg der Aspartattransaminase-Aktivität, die Alanintransaminase-Aktivität bleibt praktisch unverändert (154).

\section{Nucleasen (EC 2.7.7)}

In Harnen des Menschen und verschiedener Versuchstiere findet sich eine Ribonuclease-Aktivität (saure und alkalische Ribonuclease) und eine DesoxyribonucleaseAktivität (neutrale und saure Desoxyribonuclease) $(1,99,140)$. Untersuchungen der Veränderungen dieser beiden Aktivitäten unter verschiedenen pathologischen Bedingungen erbrachten bis jetzt keinerlei signifikante, ätiologisch oder diagnostisch bedeutsame Ergebnisse (vgl. Übersicht bei 1. c. (140)).

\section{Sulfatasen (EC 3.1.6)}

Im menschlichen Harn liegt regelmäßig eine SulfataseAktivität (Arylsulfatase A, Arylsulfatase B) vor. Bei Nierenveränderungen (Tuberkulose, Tumoren (21, 50)) steigen die Sulfatasen des Harnes an, ebenso bei Kindern mit Mastocytose (28). Es gibt - beim gegenwärtigen Stand unseres Wissens - nur eine einzige Erkrankung, bei der keine Arylsulfatase A-Aktivität im Harn vorliegt: die metachromatische Leukodystrophie. Bei dieser Erkrankung bewährte sich die Untersuchung des Harnes auf das Vorhandensein oder Nichtvorhandensein der Arylsulfatase $A$ als diagnostischer Test (8). 
$\alpha$ - und $\beta$-Glucosidase (EC 3.2.1.20; 3.2.1.21)

Die $\alpha$-Glucosidase-Aktivität des Harnes entstammt ausschließlich der Niere; ein derartiges Enzym kommt im Serum nicht vor. Die Beobachtung einer gesteigerten $\alpha$-Glucosidase-Aktivität im Harn bei Hepatitis beweist das Auftreten einer Nierenzellschädigung bei schwerer Leberstoffwechselstörung (19). Die $\beta$-Glucosidase-Aktivität imHarn fand sich bei Morbus Gaucher verringert(199).

\section{Urokinase}

Als Urol:inase bezeichnet man eine Harnprotease, die Plasminogen aktiviert. Die Urokinase des menschlichen (und tierischen) Harnes stammt aus der Niere, was in zahlreichen Versuchen experimentell bewiesen werden konnte (86, 140, 162). Das Molekulargewicht der Urokinase beträgt 53000 . Theoretisch wäre also eine glomeruläre Filtration (und Rückresorption in den Tubuli) möglich; andererseits dürfte es sich bei der Urokinase nur um ein Bruchstück der wesentlich größeren Plasminogenaktivatoren anderer Körperflüssigkeiten und Organe handeln. Beim Niereninfarkt und nach hypoxischer Nierenschädigung wurde ein Anstieg der Urokinaseausscheidung beobachtet $(140,180)$. Bei Niereninsuffizienz und bei Carcinose sinkt die Urokinaseausscheidung ab $(86,96,140,166,204)$. Eine diagnostische Bedeutung kommt den Bestimmungen der Urokinaseausscheidung nicht $z u$. Über die therapeutische Bedeutung der reinen Urokinase wurde an anderer Stelle referiert (86).

Kallikrein (EC 3.4.4.21)

Unter der Bezeichnung „Kallikreine“ faßt man Proteasen zusammen, die Kinine und Kallidine aus ihren Vorstufen aktivieren (140). Die Harnkininogenase stammt aus der Niere (201). Bisher wurde nur das Verhalten der Kallikreinausscheidung im Harn bei Nierentransplantationen untersucht: bei toleriertem Transplantat steigt die Kallikreinausscheidung im Harn an, bei beginnender Abstoßung sinkt sie hingegen ab (191). Dieses Verhalten steht im Gegensatz zum Verhalten aller anderen bisher untersuchten Harnenzyme.

\section{Lactatdehydrogenase (EC 1.1.1.27)}

Über kaum eine andere Enzymaktivität des menschlichen Harnes liegen bisher so viele Untersuchungen vor wie über die Lactatdehydrogenase. Eine Auftrennung der verschiedenen Isoenzyme zeigt die Herkunft der Harn-Lactatdehydrogenase aus verschiedenen Quellen: Nierenzellen, Blutzellen, Prostata, Samenflüssigkeit, Serum; für Routineuntersuchungen lohnt jedoch der Aufwand einer Auftrennung der Lactatdehydrogenase in Isoenzyme nicht, da selbst Veränderungen der einzelnen Fraktionen noch keine sicheren diagnostischen Schlüsse zulassen $(39,45,76)$.

Bei einer großen Zahl von Nierenerkrankungen steigt die Lactatdehydrogenase-Aktivität des Harnes an: bei Nephrosen $(77,169)$, bei Proteinurie (30), bei Erythrocyturie (32), bei Tubulusnekrose (169), bei bakteriellen Infektionen $(24,78)$, beim Niereninfarkt $(64,101)$, bei Nierenschäden als Folge einer Hypertonie, bei Zysten- niere, bei akuter Glomerulonephritis, bei renalem Erythematodes, bei schwerer Glomerulussklerose (188), sowie bei Abstoßung einer transplantierten Niere (81, 134), wobei in diesem Fall auch die Lactatdehydrogenase-Aktivität im Serum ansteigt (134). Die bei Proteinurie (30) und Erythrocyturie (32) auftretende Erhöhung der Lactatdehydrogenase-Aktivität im Harn steht in keiner direkten Relation zur Schwere der zugrundeliegenden pathophysiologischen Veränderung (Proteinurie, Erythrocyturie), da meist im Rahmen der Grundkrankheit noch andere Quellen dieses Harnenzyms mitbetroffen sind.

Besonders hohe Aktivitäten der Lactatdehydrogenase im Harn beobachtete man bei malignen Tumoren des Urogenitaltraktes wie Nierencarcinomen $(5,17,40,41)$, Blasencarcinomen (40,176, 187), Cervixcarcinomen (187) und Prostatacarcinomen $(181,202)$. Aus diesem Grund wurde in größeren Untersuchungsreihen geprüft, ob nicht Bestimmungen der Lactatdehydrogenase-Aktivität des Harnes zur Diagnose von malignen Tumoren des Urogenitaltraktes verwendet werden könnten, insbesondere da in Einzelfällen auch sogenannte „stumme“" Malignome mit einer Erhöhung der Lactatdehydrogenase-Aktivität des Harnes einhergingen. Systematische Untersuchungen ergaben jedoch, daß einerseits bei Malignomen des Urogenitaltraktes das Auftreten einer gesteigerten Lactatdehydrogenase-Aktivität im Harn nicht in jedem Fall erfolgt (42) - in einem Kollektiv sogar nur in $76 \%$ der Fälle (52) - und daß andererseits hinsichtlich der Erhöhung der Lactatdehydrogenase-Aktivität im Harn keine signifikanten Unterschiede zwischen benignen und malignen Veränderungen im Urogenitaltrakt (insbesonders Niere und ableitende Harnwege) bestehen (48, 91, 116, 123, $167,174)$. Auftrennungen der Lactatdehydrogenase des Harnes in Isoenzyme ergaben ferner - entgegen der ursprünglichen Annahme - daß die Lactatdehydrogenase des Harnes bei Malignomen keineswegs in erster Linie den Tumorzellen entstammt $(65,103)$. Wenn keine Pyurie vorliegt, lassen sich Bestimmungen der Lactatdehydrogenase-Aktivität des Harnes eventuell als Screening für Tumoren des Urogenitaltraktes verwenden $(98,184)$. Die Mehrzahl der klinischen Untersuchungen über die Veränderungen der Lactatdehydrogenase-Aktivität des Harnes weist darauf hin, $\mathrm{da} B$ das Vorliegen einer normalen Lactatdehydrogenase-Aktivität schwerere akute Veränderungen in der Niere und den ableitenden Harnwegen äußerst unwahrscheinlich macht (52), aber keineswegs ausschließt. An einem größeren Kollektiv von Nierenerkrankungen wurde festgestellt, daß in etwa $70 \%$ der Fälle eine erhöhte Lactatdehydrogenase-Aktivität des Harnes vorliegt, in etwa 30\% der Fälle eine Erhöhung der alkalischen Phosphatase im Harn vorhanden ist und nur in etwa $7 \%$ der Fälle die Muramidase-Aktivität des Harnes gesteigert ist (68). Es muß jedoch darauf verwiesen werden, daß andere Autoren über eine wesentlich höhere Inzidenz der Enzymaktivitätssteigerungen bei akuten Nierenerkrankungen berichtet haben. 
Eine hypoxische Nierenschädigung - wie z. B. beim Herzinfarkt (38) - bewirkt ebenfalls einen Anstieg der Lactatdehydrogenase-Aktivität des Harnes. Im Tierversuch (Ratte) verursacht eine hypoxische oder toxische Nierenschädigung ebenfalls einen Anstieg der Lactatdehydrogenase-Aktivität des Harnes (138, 140, 143).

Bei Nierenreizung durch Acetylsalicylsäure erfolgt eine Steigerung der Lactatdehydrogenase-Aktivität des Harnes $(46,97,129)$. Nach ihrem zeitlichen Ablauf läßt diese Steigerung zwei Gipfel erkennen: sofort nach Eintritt der Nierenreizung als Ausdruck der toxischen Schädigung (erste 24 Stdn.-Harnportion nach Verabreichung von hohen Dosen Acetylsalicylsäure) und zwei bis drei Tage später als Folge der Desquamation $(27,132,177)$ zahlreicher Nierenepithelien, deren Enzyme in den Harn gelangen $(141,148)$.

\section{Leucinaminopeptidase (EC 3.4.1.1)}

Im menschlichen Harn liegen vier Peptidasen vor: "Leucinaminopeptidase"(Aminosäure-arylamidase), Glycinaminopeptidase, Cystinaminopeptidase und Carboxypeptidase; von diesen wurde nur die Leucinaminopeptidase genauer untersucht. Verschiedene Nierenveränderungen führen zu einem Anstieg der Leucinaminopeptidase-Aktivität des Harnes, wobei die auslösenden Mechanismen zum Teil außerbalb der Niere liegen. Unter folgenden sieben pathlogischen Bedingungen kommt es zur Erhöhung. der Leucinaminopeptidase-Aktivität des Harnes (vgl. l. c. (136)):

\section{Bei toxischer Nierenschädigung:}

Ebenso wie Nierengifte bei der Ratte (Natriumtetrathionat, Sublimat (136) oder Schlangengift $(137,160)$ ) führt auch beim Menschen die Auslösung einer toxischen (chemischen) Nierenschädigung oder eines akuten Tubulusnekrose $(14,173,193)$ zu einem Anstieg der Leucinaminopeptidase-Aktivität im Harn; besonders hohe Werte finden sich, wenn die Schädigung die proximalen, besonders Leucinaminopeptidasereichen Tubulusabschnitte betrifft. Auch bei Resorption nierentoxischer Substanzen durch die Haut läßt sich eine Erhöhung der Leucinaminopeptidase-Aktivität im Harn feststellen (13). Von klinisch-pharmakologischem Interesse scheint die Tatsache, da $B$ bei medikamentöser Nierenreizung durch Sulfonamide, Streptomycin, Polymyxin B oder Kanamycin die LeucinaminopeptidaseAusscheidung im Harn ansteigt $(15,16,152,156)$. Ein gleicher Befund war nach nierenbèlastenden diagnostischen Maßnahmen (intravenöse Pyelographie (196) oder Bestimmung der Phenolrotausscheidung (14) zu etheben. Dies führte zu der Vermutung, daß nicht eine gesteigerte tubuläre Sekretion eine vermehrte renale Enzymurie zur Folge hat, da dann ein vermehrter Úbertritt von Enzymen aus den Bürstensäumen in die tubuläre Flussigkeit erfolgt. Es ist also nicht ohne weiteres angängig, eine (geringe) Steigerung der renalen Enzymausscheidung als Beweis.für das Vorliegen eines nephrotoxischen Effektes anzusehen. Am Rande sei hier nur kurz erwähnt, daß fibrinolysehemmende Medikamente (Salicylate) selbst bei Verabreichung in hohen, nierenschädigenden Dosen nur einen geringen Anstieg der Leucinaminopeptidase-Aktivität der Harnes hervorrufen, was im Gegensatz zum Verhalten anderer, aus der Niere stammender Harnenzyme steht (141) (vgl. Pkt. 7).

\section{Bei akuten entzündlichen Prozessen der Niere:}

Nicht nur bei akuter Glomerulonephritis (14) sondern auch bei Pyelonephritis (14) erfolgt eine Steigerung der Leucinaminopeptidase-Aktivität des Harnes, bedingt durch die Permeabilitätsstörung an den Nierenepithelien und durch ein vermehrtes Zugrundegehen enzymreicher Zellen. Interessanterweise liegt auch nach einer Entbindung eine erhöhte Leucinaminopeptidase-Aktivität im Harn vor, wobei die Fortdauer der erhöhten Enzymausscheidung auf die Entwicklung einer Pyelonephritis hinweist (118). Bei chronischen Nierenveränderungen findet sich eine praktisch normale Leucinaminopeptidase-Aktivität im Harn (173).

\section{Bei Störung der glomerulären Filtration:}

Eine Störung der glomerulären Filtration ermöglicht einen Ubertritt der Leucinaminopeptidase des Serums in den Harn (vgl. 1. c. $(14,94)$ ).

\section{Bei hypoxischer (hämodynamischer) Nieren- schädigung:}

Nach hypoxischer Schädigung der Niere - z. B. nach Herzoperationen (14) oder nach Auslösung eines vaskulären Schocks $(135,143)$ - steigt die Leucinaminopeptidase-Aktivität im Harn an (Abstoßung der Bürstensäume, Permeabilitätsstörungen). Der Anstieg der Leucinaminopeptidase-Aktivität im Harn läßt sich zur Beurteilung der Schwere eines Schocks (Intensität und Dauer der renalen Hypoxie) heranziehen; im Tierversuch konnte der Einfluß verschiedener Pharmaka auf vaskuläre Schockformen (Histaminschock, anaphylaktischer Schock, anaphylaktoider Schock) durch Messung der Leucinaminopeptidase-Aktivität bestimmt werden (143).

\section{Bei Tumoren des Urogenitaltraktes:}

Während Nierentumoren nur zu einer relativ geringen Steigerung der Leucinaminopeptidase-Aktivität des Harnes führen (im Vergleich zu anderen Enzymen wie z. B. der Lactatdehydrogenase), bewirken Tumore des weiblichen Genitalapparates eine kräftige Steigerung; regelmäßige postoperative Kontrollen der Leucinaminopeptidase-Aktivität des Harnes eignen sich gut zur frühzeitigen Erkennung eines Rezidivs (170).

\section{Bei Tumoren und bei Zellzerfall außerhalb des Urogenitalsystems:}

Verschiedentlich (vgl. 1. c. (136)) wurde über einen Anstieg der Leucinaminopeptidase-Aktivität des Harnes 
bei malignen Tumoren außerhalb des Urogenitaltraktes berichtet; besonders hervorgehoben wurde die Erhöhung der Leucinaminopeptidase-Aktivität im Serum und im Harn (jedoch keine glomeruläre Filtration!) bei Pankreascarcinom $(67,69)$. Die erhöhte renale Enzymurie geht auf eine Nierenschädigung durch die toxischen Stoffwechselprodukte der Tumorzellen zurïck. Besonders hohe Werte finden sich nach einer Bestrahlung maligner Tumoren, da hier in erhöhtem $\mathrm{Maße}$ toxische Substanzen freiwerden $(11,12,13)$. Die Steigerung der Leucinaminopeptidase-Aktivität des Harnes bei Verbrennungen (14) dürfte über einen gleichartigen Mechanismus zustandekommen.

\section{Bei Aktivierung renalen Plasminogens:}

Beim Menschen - ebenso wie bei der Ratte - wurde beobachtet, daß die Verabreichung von Streptokinase zu einer Erhöhung der Leucinaminopeptidase-Aktivität des Harnes führt (83). Streptokinase beeinflußt den Plasminogen-Proaktivator und dieser aktiviert (renales) Plasminogen. Renales Plasmin aktiviert renale Peptidasen, die wiederum für die Peptidase-Aktivität im Harn verantwortlich sind. Auch Vasopressin erhöht die Fibrinolyse und damit die Aktivität der Leucinaminopeptidase im Harn (146). Antifibrinolytica wie $\varepsilon$ Aminocapronsäure oder Aminomethylcyclohexancarbonsäure $(140,143)$ und Salicylate $(141,185)$ bewirken über den oben angeführten Mechanismus ein Absinken der Leucinaminopeptidase-Aktivität des Harnes. Im Tierexperiment konnte gezeigt werden, daß die bei der Pathogenese allergischer Reaktionen beteiligten enzymatischen Mechanismen keineswegs nur direkt zur Erhöhung proteolytischer Aktivitäten im Harn führen, sondern daß hier auch die Aktivierung des fibrinolytischen Potentials (Nebeneffekt im anaphylaktischen Schock) von großer Bedeutung ist (143). Besonders deutlich wurde dies bei Untersuchungen unter der Einwirkung antifibrinolytischer Substanzen. Die Tatsache der Abhängigkeit der Leucinaminopeptidase-Aktivität des Harnes vom Zustand des fibrinolytischen Systems wurde bisher nur in experimentellen Untersuchungen ausgenützt; hier konnte z. B. die Wirkung verschiedener Pharmaka auf den anaphylaktischen Schock ausgezeichnet beurteilt werden.

Durch gleichzeitige Bestimmung anderer, nicht vom fibrinolytischen System abhängiger Harnenzyme ließen sich zum Teil interessante Rückschlüsse auf Mechanismen vaskulärer Schockreaktionen und ihrer Beeinflußbarkeit gewinnen (143).

\section{ß-Glucuronidase (EC 3.2.1.31)}

Im menschlichen Harn ist regelmäßig eine $\beta$-Glucuronidase-Aktivität nachweisbar (66). Es ist auch schon gelungen, das Enzym rein darzustellen (82, 127). Die $\beta$-Glucuronidase des Harnes stammt aus den Tubuluszellen der Niere (Lysosomen) und aus den Epithelien der ableitenden Harnwege. Besonders reich an $\beta$ -
Glucuronidase scheint das Blasenepithel, da die Flüssigkeit von Blasenspülungen hohe Aktivitäten dieses Enzyms aufweist (165). Auch Drüsensekrete des Genitaltraktes (Präputialdrüsen) tragen zur $\beta$-Glucuronidase-Aktivität des Harnes bei (31).

Alle akut-entzündlichen und toxischen Nierenveränderungen gehen mit einer Steigerung $\operatorname{der} \beta$-Glucuronidase-Aktivität im Harn einher: Pyelonephritis $(9,70)$, Nierentuberkulose (21), renaler Erythematodes (70) und akute Tubulusnekrose (70), ebenso die Abstoßungsreaktion einer transplantierten Niere (70). Während selbst bei fehlender Bakteriurie eine hohe $\beta$-Glucuronidase-Aktivität im Harn (zusammen mit einer hohen Katalase-Aktivität) als Zeichen für eine beginnende Pyelonephritis bei Hochdruckniere angesehen wird (171) (Hypertonie-bedingter Nierenzellschaden nicht auszuschließen!), zeigen bakterielle Infektionen der unteren Harnwege in der Regel eine normale $\beta$-Glucuronidase-Aktivität im Harn (9). Wurmerkrankungen der Blase manifestieren sich oft mit einer Erhöhung der $\beta$-Glucuronidase-Aktivität im Harn $(58,59)$. Als Ursache hierfür werden die desquamativen und entzündlichen Prozesse, die mit der Durchwanderung von Wurmeiern durch das Blasenepithel verbunden sind, angesehen (60). Als Screening für eine Schistosomiasis der Blase läßt sich die $\beta$-GlucuronidaseBestimmung im Harn allerdings nicht verwenden, da die Erhöhung der Enzymaktivität nur zu bestimmten Zeiten auftritt und da in tropischen Ländern das Harnsammeln über längere Perioden auf besondere Schwierigkeiten stößt (61).

Chronische Erkrankungen der Niere (chronische inaktive Pyelonephritis, chronische Glomerulunephritis) weisen eine normale $\beta$-Glucuronidase-Aktivität im Harn auf (70).

Besonderes Interesse erregte die Beobachtung, daß Nierentumoren (21) und besonders Blasencarcinome $(22,100,109,110,115)$ von hohen Aktivitäten der $\beta$-Glucuronidase im Harn begleitet sind. $\mathrm{Da}$ in Einzelfällen die Enzymaktivität auch nach Entfernung des Tumors hoch blieb, wurde vermutet, daß die gesteigerte Enzymaktivität die Ursache der Tumorbildung wäre $(22,108)$. Diese Vermutung wurde jedoch durch weitere Untersuchungsergebnisse widerlegt; die hohe $\beta$-Glucuronidase-Aktivität im Harn stellt nur eine Folge der Tumoren dar (91). In größeren Untersuchungsreihen wurde festgestellt, daß zwischen Populationen mit hoher Inzidenz an Blasencarcinomen und Populationen mit niedriger Inzidenz solcher Tumoren kein signifikanter Unterschied in $\operatorname{der} \beta$-Glucuronidase-Aktivität des Harnes besteht (125). Auch bei Patienten mit malignen Tumoren außerhalb des Harntraktes wurde eine Steigerung der $\beta$-Glucuronidase-Aktivität im Harn beobachtet $(115,124,189)$. Die Bestrahlung von Cervixcarcinomen führt direkt zu einer Erhöhung der $\beta$-Glucuronidase-Aktivität im Harn - und nicht über den Umweg der Nierenschädigung -, da die $\beta$-Glucuronidase der zerfallenden Tumorzellen in den Harn gelangt (189). 
Bei Arbeitern bestimmter chemischer Industrien werden einige Cancerogene als Glucuronide im Harn ausgeschieden; unter dem Einfluß $\operatorname{der} \beta$-Glucuronidase des Harnes wird das Cancerogen freigesetzt und kann nun eine Carcinombildung in der Blase auslösen. Um dies zu verhindern, wurde die prophylaktische Verabreichung von 1,4-Saccharolacton ( $1-4 \mathrm{~g} / \mathrm{Tag}$ ) empfohlen; hierdurch wird die $\beta$-Glucuronidase-Aktivität des Harnes auf $10-20 \%$ des Ausgangswertes verringert $(23,111)$. Übrigens hemmt auch Glucuronolacton, ein normaler Harnbestandteil, die Aktivität der $\beta$-Glucuronidase (59).

Die $\beta$-Glucuronidase der Niere ist in den Lysosomen der Tubulusepithelien lokalisiert. Dementsprechend wurde ein weitgehend gleichartiges Verhalten wie bei den anderen lysosomalen Enzymen im Harn vermutet. Tatsächlich fand sich auch eine gute Parallelität zwischen den Veränderungen $\operatorname{der} \beta$-Glucuronidase und der $\mathrm{Ga}$ laktosidase im Harn (34). Weniger gut war die Relation zur Muramidase im Harn, da dieses Enzym auch aus dem Serum stammt, insbesondere bei geringfügigen pathologischen Störungen.

Um den Schwierigkeiten der langen Harnsammelperioden $z u$ begegnen wurde versucht, das Verhältnis von $\beta$-Glucuronidase im Harn zur Kreatininausscheidung zu bestimmen (88). Die erzielten Ergebnisse waren zwar zum Teil recht gut vergleichbar, erbrachten aber keinen Fortschritt in diagnostischen Belangen.

Heute werden Untersuchungen der $\beta$-GlucuronidaseAktivität des Harnes nur noch selten durchgeführt, die Ergebnisse derartiger Bestimmungen sind in ihrem Aussagewert den Resultaten anderer Enzymveränderungen (Lactatdehydrogenase, alkalische Phosphatase, Leucinaminopeptidase) unterlegen. Auch die experimentellen Untersuchungen an Ratten ergaben an verschiedenen Modellen eine Überlegenheit anderer Enzymbestimmungen gegenüber $\operatorname{der} \beta$-Glucuronidase (163).

\section{Alkalische Phosphatase (EC 3.1.3.1)}

Im menschlichen Hatn ist regelmäßig eine alkalische Phosphatase-Aktivität nachweisbar; bei stark verdünnten Harnen empfiehlt sich mitunter eine Einengung. Unter normalen Bedingungen stammt die alkalische Phosphatase des Harnes ausschließlich aus der Niere. Biochemische Untersuchungen konnten jedoch zeigen, daß es sich bei der alkalischen Phosphatase des Harnes nur um Bruchstücke der alkalischen Phosphatase der Niere handelt (Molekulargewicht der Bruchstücke um 75000, Molekulargewicht der renalen alkalischen Phosphatase zwischen 150000 und 170000) (26). Bei exakten Auftrennungen der alkalischen Phosphatase des Harnes konnten insgesamt bis zu 10 Fraktionen solcher Bruchstücke mit enzymatischer Aktivität nachgewiesen werden (104).

Alle krankhaften Prozesse, die entweder mit einem vermehrten Zugrundegehen von Nierenzellen oder mit einer Störung der glomerulären Permeabilität verbunden sind, führen $z u$ einer Steigerung der alkalischen Phosphatase-Aktivität des Harnes: akute Glomerulone- phritis, renaler Erythematodes, Glomerulosklerose, akute Tubulusnekrose, Niereninfarkt, Adenocarcinom und Pyelonephritis (3, 4, 5, 47, 64, 68). Auch beim Blasencarcinom findet sich eine erhöhte alkalische Phosphatase-Aktivität im Harn (47). Kurzdauernde Perioden von Hypoxie - wie z. B. beim Herzinfarkt bewirken ebenfalls über eine hypoxische Schädigung der Niere (Abstoßung der Bürstensäume, Permeabilitätsstörung) einen Anstieg der alkalischen-PhosphataseAktivität des Harnes (38). Die Steigerung der alkalischen Phosphatase-Aktivität des Harnes nach Auslösung toxischer oder hypoxischer Nierenveränderungen konnte auch im Tierexperiment bestätigt werden (135, 139, 140).

Bei chronischer Glomerulonephritis ist die alkalische Phosphatase-Aktivität des Harnes unverändert (5). Die bei praktisch allen akuten und subakuten Nierenveränderungen auftretenden Erhöhungen der alkalischen Phosphatase-Aktivität im Harn machen eine spezifische Diagnostik durch Bestimmung dieser Enzymaktivität unmöglich; zur Differenzierung medizinischer und urologischer Erkrankungen ist also die alkalische Phosphatase-Aktivität des Harnes ebensowenig geeignet wie die anderen aus der Niere stammenden Enzymaktivitäten $(47,123,140)$.

Für Fragen der klinischen Pharmakologie und Toxikologie ermöglicht die Bestimmung der alkalischen Phosphatase-Aktivität im Harn bessere Aussagen als die Bestimmung vieler anderer Enzyme. So erfolgt z. B. bei Patienten nach Einnahme nephrotoxischer Medikamente wie Streptomycin, Polymyxin B oder Sulfonamiden (vgl. 1. c. $(73,165,190)$ ) ein deutlicher Anstieg der alkalischen Phosphatase-Aktivität im Harn (16). Gleiche Ergebnisse brachten Tierexperimente an Ratten. Die Verabreichung von Kanamycin, Streptomycin oder Sulfonamiden bewirkt eine signifikante Steigerung der alkalischen Phosphatase-Aktivität im Harn (152, 156, 203), ebenso wie die Verabfolgung von Acetylsalicylsäure in höherer Dosierung (148, 150, 151). Ähnlich wie bei der Lactatdehydrogenase-Aktivität (siehe dort) läßt sich Steigerung in zwei Gipfeln nachweisen (141). Die Bestimmung der alkalischen Phosphatase-Aktivität des Harnsedimentes (mehrmaliges Waschen, Aufschließung mit Ultraschall) ermöglicht eine biochemische Bestimmung der Anzahl desquamierter Zellen am 2. und 3. Tag nach Gabe von Acetylsalicylsäure (148). Coffein verstärkt die renale Enzymurie nach Acetylsalicylsäure (151), was möglicherweise für klinische Fragen (Analgetikaabusus und Nierenschaden) von Bedeutung ist.

Im Tierexperiment konnte die Korrelation von Absinken der alkalischen Phosphatase-Aktivität im Nierengewebe und Anstieg der alkalischen Phosphatase-Aktivität im Harn nach Einwirkung nephrotoxischer Agentien nachgewiesen werden (vgl. l. c. $(130,139)$ ). Beim Menschen ist bisher die Frage der histochemischen Korrelation noch nicht gelöst (44).

Interessanterweise konnte wiederholt ein Anstieg der alkalischen Phosphatasc-Aktivität des Harnes bei Pa- 
tienten mit hoher Serum-Aktivität der alkalischen Phosphatase gefunden werden $(2,37,63,120,139)$. Hier ist anzunehmen, daß die zur Erhöhung der alkalischen Phosphatase des Serums führende Grundkrankheit auch einen Nierenschaden verursacht hat, durch den die Erhöhung der alkalischen Phosphatase-Aktivität des Harnes zustandekommt.

\section{Saure Phosphatase (EC 3.1.3.2)}

Im menschlichen Harn ist regelmäßig eine saure Phosphatase-Aktivität nachweisbar. Bei Frauen (und weiblichen Versuchstieren) stammt die saure PhosphataseAktivität des Harnes ausschließlich aus der Niere, beim Mann trägt das Prostatasekret wesentlich zur sauren Phosphatase-Aktivität des Harnes bei (140, 153). Männliche Ratten zeigen im Durchschnitt eine um $50 \%$ höhere saure Phosphatase-Aktivität im Harn als weibliche Versuchstiere (153). Bestimmungen der sauren Phosphatase-Aktivität im Harn des Mannes wurden als Index für die Prostatasekretion, bzw. ganz allgemein für die androgene Aktivität empfohlen (178).

Untersuchungen der sauren Phosphatase-Aktivität im Ureterharn konnten genau zeigen, welche Niere pathologische Veränderungen aufweist; Ureterharn von der erkrankten Seite läßt eine wesentlich höhere saure Phosphatase-Aktivität erkennen als der Ureterharn von der anderen gesunden Niere (175).

\section{Harn- und Serumenzyme bei Nieren- und Herz- infarkt}

Über die Möglichkeiten der Differenzierung von Nierenund Herzinfarkt durch enzymatische Untersuchungen wurde bereits viel diskutiert. An dieser Stelle soll deshalb eine Zusammenstellung der hierzu vorliegenden Befunde gegeben werden. Beim Herzinfarkt gelangen zahlreiche Enzyme (Lactatdehydrogenase, Aspartattransaminase $u$. a.) aus dem zugrundegehenden Muskel in das Serum; regelmäßig findet sich deshalb nach Herzinfarkt eine Erhöhung der Lactatdehydrogenase- und Aspartattransaminase-Aktivität im Serum. Beim Niereninfarkt (und zum Teil auch bei anderen schweren Nierenveränderungen) treten Enzyme der zugrundegehenden Nierenzellen in das Serum über; so ließen sich Erhöhung der Lactatdehydrogenase (49, 53, 101, $121,134,192)$, der Aspartattransaminase $(56,64,192)$ der Isocitratdehydrogenase (EC 1.1.1.41) (126, 144), der Cholinesterase (EC 3.1.1.3) $(145,183)$ und der Glutamatdehydrogenase (EC 1.4.1.2) (147) im Serum nachweisen. Bezüglich der Veränderungen von Serumenzymaktivitäten liegen also zwischen Herz- und Niereninfarkt keine qualitativen Unterschiede vor.

Eine ähnliche Feststellung trifft auch auf die Enzymveränderungen im Harn zu. Beim Herzinfarkt kommt es zu einer mehr oder weniger ausgeprägten hypoxischen Schädigung der Niere, was zu einer Steigerung der renalen Enzymurie führt. So wurden erhöhte Aktivitäten der Lactatdehydrogenase-, alkalische Phosphatase(38) und Aspartattransaminase-Aktivität (87, 179) im Harn nach Herzinfarkt beobachtet. Beim Niereninfarkt gehen zahlreiche Nierenzellen zugrunde, deren Enzyme im Harn erscheinen. Somit lassen auch Bestimmungen der gesteigerten renalen Enzymurie eine sichere Differenzierung zwischen Herz- und Niereninfarkt nicht $z u$.

\section{Ausblick}

Bestimmungen der aus dem Serum stammenden Harnenzymaktivitäten nehmen einen festen Platz in der medizinischen Diagnostik ein und werden auch weiterhin - wenn auch nur in eingeschränktem $\mathrm{MaBe}$ immer wieder angewendet werden.

Bestimmungen der aus der Niere stammenden Harnenzymaktivitäten (Lactatdehydrogenase, Leucinaminopeptidase, $\beta$-Glucuronidase, alkalische Phosphatase) eignen sich gut als Screening für das Vorliegen schwererer Veränderungen in der Niete und in den ableitenden Harnwegen (52, 63, 102, 112, 113, 194). Das Vorliegen normaler Enzymaktivitäten macht schwerere Störungen unwahrscheinlich. Eine Spezifität der Diagnose ist jedoch nicht gegeben, d. h. der Befund einer erhöhten renalen Enzymurie kann nicht auf eine spezifische Erkrankung zurückgeführt werden. Für den steigenden Einsatz enzymatischer Untersuchungsmethoden in der medizinischen und urologischen Diagnostik spricht der geringe Aufwand solcher Untersuchungen und das Fehlen einer Belastung des Patienten. Vielleicht wird es möglich sein durch Ausarbeitung entsprechender Bezugssysteme (wie etwa des Enzym-Kreatinin-Index) das Harnsammeln über längere Perioden überflüssig zu machen. Als Nachteil der Interpretation von Untersuchungsergebnissen der renalen Enzymurie werden die heute noch recht geringen Kenntnisse über das Verhalten von Enzymaktivatoren und -inhibitoren unter pathologischen Bedingungen empfunden.

Bestimmungen der aus Drüsensekreten des Urogenitaltraktes stammenden Harnenzymaktivitäten wurden vereinzelt zur Bestimmung des funktionellen $\mathrm{Zu}$ standes genitaler Drüsen empfohlen, haben aber in die Routinediagnostik noch nicht Eingang gefunden.

In Einzelfällen (z. B. bei der metrachromatischen Leukodystrophie) erwies sich die Untersuchung einer bestimmten Enzymaktivität im Harn von außerordentlich hohen diagnostischen Wert. Weitere Untersuchungen könnten hier neue Gesichtspunkte erbringen und das diagnostische Spektrum erweitern.

\section{Literatur}

1. Aleksandrowicz, J. und L. Spirer, Sang 26, 212 (1955). 2. Allen, H. und M. A. Spellberg, Arch. Int. Med. Chicago, 120, 667 (1967). - 3. Amador, E., L. E. Dorfman und W. E. C. WACKER, Ann. Int. Med. 62, 30 (1965). - 4. AMador,
E., Th. S. Zimmermann und W. E. C. Wacker, J. Amer. Med. Ass. 185, 769 (1963). - 5. AMador, E., Th. S. ZimMErmanN und W. E. C. WaCker, J. Amer. Med. Ass. 185, 953 (1963). - 6. Amelung, O. und H. D. Horn, Dtsch. med. Wschr. 81, 1701 

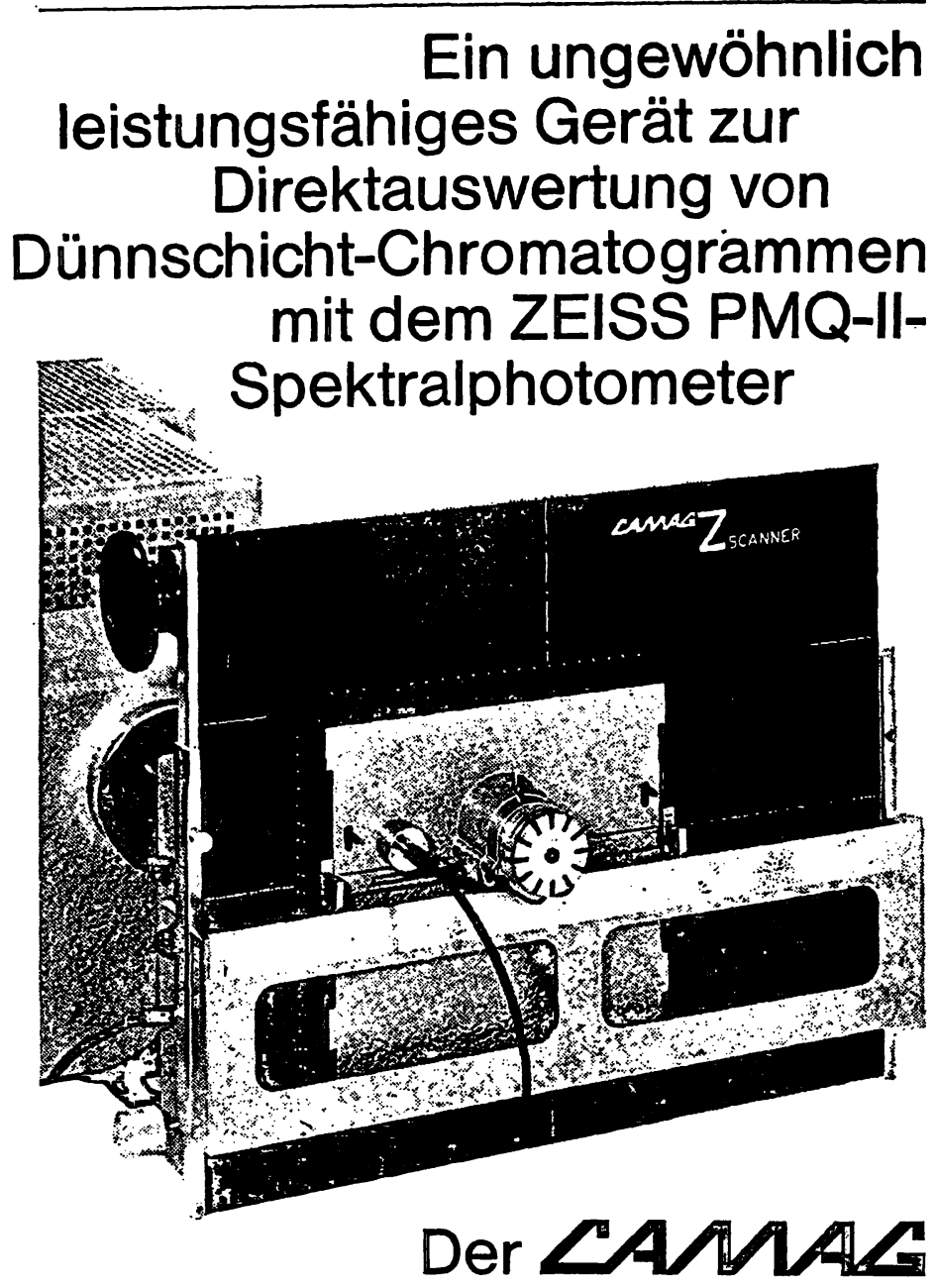

Z-SCANNER erlaubt alle Arten der Remissionsmessung

Quantitative Bestimmungen durch:

- Lichtabsorptionsmessungen im sichtbaren Bereich

- Absorptionsmessungen im UV-Bereich ab $220 \mathrm{~nm}$

- Fluoreszenzmessungen

- Messungen der Fluoreszenzlöschung Qualitative Untersuchungen:

- Aufnahme von Lichtabsorptionsspektren

- Aufnahme von UV-Absorptionsspektren

- Aufnahme von Fluoreszenzspektren

Verlangen Sie unseren Prospekt 761-100, er informiert Sie ausführlich.

Auch unser Angebot wird Ihnen zusagen

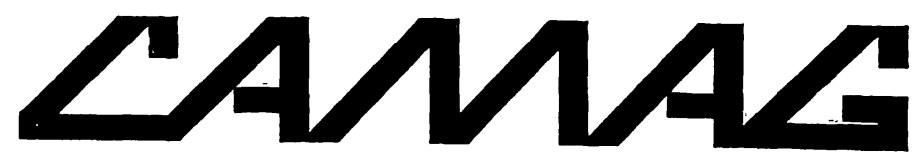

Chemie-Erzeugnisse und Absorptionstechnik AG

4132 Muttenz/Schweiz Homburgerstrasse 24

Telefon (061) 531430
1000 Berlin 45

Baseler Strasse 65

Telefon (0311) 737077

\section{Experimentelle Einführung in die anorganische Chemie}

Neu herausgegeben von W. KLEMM und W. Fischer 63.-70. Auflage

Oktav. XII, 228 Seiten. 1970. Balacron flexibel DM 21,-

Die Kürzung der Dauer des Chemiestudiums führt besonders zu einer Kürzung der experimentellen Ausbildung, andererseits müssen im Anfang grundlegende Stoffkenntnisse anhand der wichtigsten Ordnungsprinzipien vermittelt werden.

Um den heutigen Forderungen einer solchen Einführung Rechnung zu tragen, wurde das Werk überarbeitet und teilweise geändert. Während vom experimentellen Teil nur einige auf die analytische Chemie bezogene Versuche gestrichen wurden, erfuhren die theoretischen Abschnitte bei der Anpassung auf den heutigen Stand stärkere Änderungen. Neu gestaltet wurden insgesamt die Kapitel: Anwendungen des Massenwirkungsgesetzes, Oxidations-Reduktions-Potentiale. Bei der Behandlung von Säure-Basen-Gleichgewichten wurde der historischen Entwicklung von Davy und Liebig über Arrhenius und Ostwald zu Brönsted Rechnung getragen; im weiteren Verlauf werden aber nur noch die Brönstedschen Definitionen verwaridt.

\section{$W$
$\mathrm{DE}$
$\mathrm{G}$}

\section{Walter de Gruyter Berlin - New York}

\section{Neves Kreisspital in Morges (Genfersee)}

Für diese Anstalt, die sich gegenwärtig in Bau befindet, und auf Herbst 1972 fertiggestellt sein soll, wird hiermit der Posten für einen

\section{AKADEMIKER \\ mit Erfahrung in Biochemie, zur Leitung der Laboratorien ausgeschrieben.}

Auskunft auf schriftliches Verlangen erteilt: M. André Golaz, Dịrektor, Neues Kreisspital, Chemin de la Grosse Pierre 16, CH 1110 Morges, Schweiz 
(1956). - 7. Amelung, O., H. D. Horn und E. Schröder, Klin. Wschr. 36, 963 (1958). - 8. Austrn, J., D. Armstrong, L. SHEArER und D. MCA fee, Arch. Neurol. Psychiatr., Chicago, 14, 259 (1966). - 9. BANK, N. und S. H. BAILINE, N. England J. Med. 272, 70 (1965). - 10. BAUR, H., Gastroenterologia Basel, 84, 283 (1955); Helvet. med. acta 22, 414 (1955). - 11. BECKER, J., H. EbNER und K. H. KärCHER, Strahlentherapie 109, 357 (1959). 12. Bergmann, H., Arch. klin. exp. Dermat. 219, 500 (1964). 13. Bergmann, H. und G. F. KlostermanN, Arch. klin. exp. Dermat. 218, 603 (1964). - 14. BergmanN, H. und F. Scheler, Klin. Wschr. 42, 275 (1964). - 15. BergmanN, H. und F. Truss, Med. Welt 1964, 1760. - 16. BergmanN, H., F. Truss und K. Zreb, Verh. Dtsch. Ges. Urol. 21, 197 (1966). - 17. Boetriger, L. E., S. Lindstedt und T. von Schreeb, Acta chir. Scand. 132, 356 (1966). - 18. BoGATZKr, M., Fortschr. Med. 83, 859 (1965). 19. Bonini, P. A. und C. Franzint, Biochim. Biol. sper. 7, 47 (1968). - 20. Bolt, R. J., H. M. Pollard und A. Carballo, J. Laborat. Clin. Med., S. Louis, 43, 335 (1954). - 21. Boyland, E., D. M. Wallace und D. C. Williams, Brit. J. Cancer 9, 62 (1955). 22. Boyland, E., D. M. Wailace und D. C. Williams, Brit. J. Urol. 27, 11 (1955). - 23. BoyLand, E., D. M. WALLACE und D. C. Whliams, Brit. J. Cancer 11, 578 (1957). - 24. Brenner, B. M. und V. E. GILBERT, Amer. J. Med. Sc. 245, 31 (1963). 25. Burghartz, N. und E. Bossfeld, Klin. Wschr. 32, 182 (1954). - 26. ButTER wORTF, P. J., Biochem. J. 107, 467 (1968). 27. Clausen, E. und B. Harvald, Acta med. Scand. 170, 469 (1961). - 28. Clausen, J. und G. Asboe-Hansen, Clin. Chim. Acta (Amsterdam), 16, 131 (1967). - 29. Cofren, A. M. und W. G. W ALKER, Clin. Res. 15, 354 (1967). - 30. Coltorti, M., A. Ascione, G. Giustr und A. DI Srmone, Riforma med. Napoli, 47, 1313 (1962). - 31. Coonrod, D. und P. Y. Paterson, J. Laborat. Clin. Med., S. Louis, 73, 6 (1969). - 32. CRockson, R. A., Lancet, London, 1961/I, 140. - 33. Cummins, A. J., Ann. intern. Med. 52, 1213 (1960). - 34. Davidson, W. D., Clin. Res. 15, 355 (1967). - 35. Dicker, S. E. und M. G. EgGLeton, J. Physiol. 157, 351 (1961). - 36. Dicker, S. E. und M. G. EggleTON, Lancet, London 1963/II 467. - 37. DieTZ, A. A. und L. K. Hodges, Clin. Chim. Acta, (Amsterdam) 15, 393 (1957). - 38. Dietz, A. A., L. K. Hodges und D. T. Foxworthy, Clin. Chem. (New York) 13, 359 (1967). - 39. Dioguardi, N., G. Fiorelil, G. Ideo und G. Emanueler, Farmaco (Peria) 21, 334 (1966). - 40. Dorfman, L. E., E. AMador und W. E. C. Wacker, Biochem. Clinics 2, 41 (1963). - 41. Dorfman, L. E., E. AMADOR und W. E. C. WACKer, J. Amer. Med. Ass. 184, 1 (1963). - 42. Dubach, U. C., Oncologia 19, 254 (1965). - 43. Dubach, U. C., Klin. Wschr. 43, 753 (1965). - 44. DUBACH, U. C., Polskie arch. med. wewn. 36, 577 (1966). - 45. DubACH, U. C., Helvet. med. acta 33, 139 (1966). - 46. Dubach, U. C. und W. Jösch, Schweiz. med. Wschr. 97, 1314 (1967). - 47. DuBACH, U. C. und G. Padirina, Klin. Wschr. 44, 180 (1966). - 48. Dubach, U. C. und R. Rediger, Urol. int. 17, 65 (1964). - 49. Duggan, M. L., J. Urol., Baltimore 90, 669 (1963). - 50. DzLalosYNskr, L. M., Clin. Chim. Acta, (Amsterdam) 2, 542 (1957). - 51. Ehrenreich, R. und P. GrüNEIS, Enzymol. biol. clin. 10, 398 (1969). - 52. EMERSON, P. und M. N. MORGAN, Brit. J. Utol. 38, 551 (1966). 53. ERICKSON, R. J. und D. R. Morales, N. England, J. Med. 265, 478, 531 (1961). - 54. EsCHER, J., E. RINGDAL und P. Schinars, Schweiz. med. Wschr. 97, 1753 (1967). - 55. FAarvang, H. J., Proc. Soc. exp. Biol. Med. 98, 89 (1958). - 56. Frahm, C. J. und R. Folse, J. Amer. Med. Ass. 180, 209 (1962). 57. Franzini, C. und S. Moda, J. Clin. Path., London 18, 775 (1965). - 58. FRIPP, P. J., Nature (London) 188, 507 (1960). 59. FRIPP, P. J., Biochem. J. 89, 75P (1963). - 60. FRIPP, P. J., Brit. J. Cancer 19, 292 (1965). - 61. FRIPP, P. J., Bull. World Health Organizat., N. Y. 34, 423 (1966). - 62. GAMBILL, E. E. und H. L. Mason, J. Amer. Med. Ass. 188, 824 (1964). - 63. Gault, M. H., J. A. Oliver, C. Lang, M. I. Asghar und S. W. Levx, Brit. J. Urol. 39, 296 (1967). - 64. GAULT, M. H. und G. Steiner, Canad. Med. Ass. J. 93, 1101 (1965). - 65. Gelderman, A. H., H. V. Gelbonn und A. C. PeAcock, J. Laborat. Clin. Med., S. Louis 65, 132 (1964). - 66. Goldbarg, J. A., E. P. Pineda, B. M. BANks und A. M. Ruthenburg, Gastroenterology, Balti- more 36, 193 (1959). - 67. Goldbarg, J. A. und A. RuthenBURG, N. England J. Med. 259, 469 (1958). - 68. GOLDBERG, W., S. Chakrabarti und R. Filipich: Canad. Med. Ass. J. 94, 1264 (1966). - 69. Goliscri, G., Klin. Wschr. 38, 968 (1960). 70. Gonick, H. C. und A. Schapiro, Clin. Res. 15, 358 (1968). 71. Gutekunst, J. A., Dermatologica 118, 259 (1959). - 72. Harrison, J. F., G. S. Lunt, P. Scotr und J. D. BLAinse, Lancet, London 1968/1, 371. - 73. Haschek, H. und P. Porpaczy, Wien. klin. Wschr. 80, 169 (1968). - 74. HeInkEL, K., Internist 2, 362 (1961). - 75. Heinkel, K. und L. Muscitaki, Med. Welt 1964, 250. - 76. Hemingesen, L. und F. Skov, Clin. Chim. Acta (Amsterdam) 19, 81 (1968). - 77. Hess, B. und R. Raftopoulo, Dtsch. Arch. klin. Med. 204, 97 (1957). - 78. Hоввs, J. R. und S. E. Aw, Current Problems in Clin. Biochem. H. Juber, Bern 2, 281 (1968). - 79. HohINEGger, M. und E. KaISER, Klin. Wschr. 45, 1252 (1967). - 80. Hohienteger, M. und W. RaAB, Clin. Chim. Acta (Amsterdam) 28, 61 (1970). - 81. Hume, D. M., J. H. Magee, G. R. Prout, H. M. Kauffman, R. H. Cleveland, J. D. Bower und H. M. Lee, Ann. N. Y. Acad. Sc. 120, 578 (1964). - 82. Hygstedr, O. und O. R. Jagenburg, Scand. J. Clin. Laborat. Invest. 17, 565 (1965). - 83. INNERFIELD, I., R. Harvey, F. Luongo und E. Blincoe, Proc. Soc. exp. Biol. Med. 116, 573 (1964). - 84. JÄRVINEN, K. A. J., Brit. Med. J. 1958/I, 379. - 85. Jöscri, W. und U. C. DubaCh, Clin. Chim. Acta (Amsterdam) 15, 325 (1967). - 86. KAISER, E. und W. RAAB, Zschr. Vitamin-Hormon-Ferm.forsch., Wien 14, 154 (1965). - 87. Kalmansofin, R. B. und R. W. Kalmansohn, California Med. 95, 165 (1961). - 88. Kallere, H. A. und L. LAPCO, J. Urol., Baltimore 97, 352 (1967). - 89. KelleR, H. E., H. Agne, H. Mannebach und W. Leppla, Current Problems in Clin. Biochem. H. Huber, Bern, 2, 265 (1968). - 90. KeRN, W. H. und W. W. WEBSTER, Acta cytol. (Philadelphia) 8, 302 (1964). 91. KerR, W. K., M. BARKIN, J. D'Aloisio und Z. MENCZYK, Cancer 16, 633 (1963). - 92. Kirshen, R., E. E. GaMbill und H. L. MASON, Gastroenterology Baltimore 48, 579 (1965). 93. Kraus, D., Klin. Wschr. 36, 207 (1958). - 94. Klaus, D., Ärztl. Forschung 16, 9 (1962). - 95. KRAMrar, R., R. LAMBrRECHTER und W. RAAB, Wien klin. Wschr. 82, 410 (1970). - 96. KROpp, R., J. FreY und J. Jürgens, Med. Klin. 62, 1941 (1967). 97. Leathwood, P. D. und D. T. Plummer, Biochem. J. 114, 197 (1969). - 98. LeE, D. A., A. T. Cockett, B. M. Caplan und N. Chramori, J. Urol. Baltimore 95, 77 (1966). - 99. Levr, A. L. und A. Rotrino, Clin. Chem. (New York) 6, 43 (1960). - 100. Lewis, F. J. W. und C. H. J. Praice, Brit. J. Cancer 14, 106 (1960). - 101. London, I. L., P. Hoffsten, G. T. Perkoff und T. G. Pennington, Arch. Int. Med. 121, 87 (1968). - 102. LYMBEROpOULOS, S. und W. LUTZEYER, Utologe 5, 181 (1966). 103. Macalalag, E. V. und G. Prout, J. Urol. Baltimore 92, 416 (1964). - 104. Maruna, R. F. L., Clin. Chim. Acta (Amsterdam) 25, 133 (1969). - 107. Mason, E. E., F. A. Chernogoy, H. P. Gulesserian und T. C. Tector, Surg. Gyn. Obstet 122, 333 (1966). - 106. Mason, E. E. und C. Dierks, Bull. Soc. Intern. Chir. 20, 173 (1961). - 107. Mattea, E. und E. Pietra, Tumori 45, 86 (1959). - 108. Mattea, E. und E. Pretra, Tumori 45, 239 (1959). - 109. Mattea, E., E. Pietra und E. Vescia, Tumori 45, 229 (1959). - 110. Mattea, E., E. Pietra und M. R. Viola, Tumoti 45, 391 (1959). - 111. Mattea, E., E. Pietra und M. R. Viola, Tumori 45, 402 (1959). - 112. MattenHERMER, H., Dtsch. med. Wschr. 92, 2075 (1967). - 113. MATtenfrenrer, H., Current Problems in Clin. Biochem. H. Huber, Berne 1, 355 (1968). - 114. MCGeacinm, R. L. und L. A. HARGAN, J. Appl. Physiol., Wsab. 9, 129 (1956). - 115. Melicow, M. M., A. C. Uson und R. Lipton, J. Urol., Baltimore 86,89 (1961). - 116. Mirabile, C. S., G. N. Botrers und B. B. BerLin, J. Urol., Baltimore 95, 79 (1966). - 117. Moutsos, S. E., H. Stenn und A. P. Srinprro, J. Laborat. Clin. Med., S. Louis 59, 847 (1961). - 118. Mullan, D. P., J. Clin. Path., London 20, 660 (1967). - 119. Muller, A. F., R. Veyrat und A. GrandChAMP, Klin. Wschr. 46, 1241 (1968). - 120. NAvA, G. und L. Szasz, Fol. endoct. 3, 437 (1950). - 121. Nielsen, V. K., E. Kemp und Th. Laursen, Acta med. Scand. 184, 109 (1968). 122. Noble, R. E., J. S. Najarian und H. D. Brainerd, Proc. 
Soc. exp. Biol. Med. 120, 737 (1965). - 123. NosaL, T., W. S. Kiser, M. L. Robitaitle und J. W. King, Clin. Chem. (New York) 12, 542 (1966). - 124. Palazzolo, A. M. und M. PavoneMacaluso, Boll. Soc. ital. biol. sper. 38, 388 (1962) (Chem. Zbl. 134, 16993,1963$)$. - 125. Pavone-Macaluso, M., D. Di Donna und A. M. Palazzolo, Boll. Soc. ital. biol. sper. 38, 3861962 (Chem. Zbl. 134, 15092, 1963). - 126. PAZ, R. A., K. R. REES und W. G. SPECTOR, Nature (London) 195, 89 (1962). - 127. Petrengris, O. S. und W. H. Frshman, J. biol. Chemistry 237, 24 (1962). - 128. PietschimanN, H., H. Puxkande und F. Reinhard, Wien. Zschr. inn. Med. 41, 440 (1960). - 129. Plummer, D. T. und P. D. Leathwood, Biochem. J. 106, 55 P (1968). 130. Pollak, V. E., S. L. Bonting, R. C. Muehrcke und R. M. KARK, J. Clin. Invest. 39, 1386 (1960). - 131. Poser, J., A. Mojzis und J. TovareK, Rev. franc. études clin. biol. 5, 919 (1960). - 132. Prescott, L. F., Lancet 1965/II, 91. - 133. Prockop, D. J. und W. D. Davidson, Neu England J. Med. 270, 269 (1964). - 134. Prout, G. R., E. V. Macalalag und D. M. Hume, Surgery, S. Louis 56, 283 (1964). - 135. RaAB, W., Nature (London) 212, 953 (1966). - 136. RAAB, W., Wien. klin. Wschr. 78, 364 (1966). - 137. RAAB, W., Naturwissenschaften 53, 43 (1966). - 138. RAAB, W., Experientia, Basel 23, 833 (1967). 139. RAAB, W., Zschr. Vitamin-Hormon-Ferm.forsch. 15, 336 (1967). - 140. RaAB, W., Current Problems in Clin. Biochem. H. Huber, Berne 2, 17 (1968). - 141. RaAB, W., Clin. Chim. Acta (Amsterdam) 22, 535 (1968). - 142. RAAB, W., Enzymologia 36, 177 (1969). - 143. RAAB, W., Wien. klin. Wschr. 81, 631 (1969). - 144. RAAB, W., Enzymologia 37, 179 (1969). 145. RaAB, W:, Clin. Chim. Acta (Amsterdam) 24, 135 (1969). 146. RAAB, W., Wien. klin. Wschr. 81, 689 (1969). - 147. RAAB, W., Clin. Chim. Acta (Amsterdam) 24, 275 (1969). - 148. RAAB, W., Helvet. med. acta 34, 498 (1969). - 149. RAAB, W., Clin. Chim. Acta (Amsterdam) 25, 21 (1969). - 150. RAAB, W., Int. Z. klin. Pharmakol.3,174(1970). - 151. RAAB, W., Helvet. med. Acta 35, 290 (1970). - 152. RAAB, W., Clin. Chim.Acta (Amsterdam) 29, 451 (1970). - 153. RAAB, W. und E. Donhoffer, Klin. Wschr. 44, 1317 (1966). - 154. RAAB, W. und E. Donhoffer, Klin. Wschr. 45, 1254 (1967). - 155. RAAB, W. und M. HOHENEGGER, Wien. klin. Wschr. 80, 402 (1968). - 156. RAAB, W. und M. Hohenegger, Clin. Chim. Acta (Amsterdam) 20, 95 (1968). 157. RAAB, W. und M. HohENEGGER, diese Z. 7, 384 (1969). 158. RaAB, W., M. Hohenegger und E. Kaiser, Pharmacology 2, 82 (1969). - 159. RAAB, W. und E. KAISER, Klin. Wschr. 43, 345 (1965). - 160. RAAB, W. und E. KaISER, Wien. Zschr. Med. 47, 327 (1966). - 161. RAAB, W., E. KAISER und W. BABACEK, Klin. Wschr. 44, 850 (1966). - 162. RAAB, W., E. KAISER und W. BABACEK, Zschr. Biol. 115, 310 (1966). - 163. RAAB, W., R. Kramar und R. LAMbrechter, Ärztl. Lab. 16, 288 (1970). - 164. Relman, A. S. und W. B. Schwartz, N. England J.Med.255, 195 (1956). - 165. RICHTERICH, R. und H. DAUWALDER, diese Z. 4, 105 (1966). - 166. RigGenBACH, N. und K. N. v. Kaulla, Cancer 14, 889 (1961). - 167. Riggns, R. S. und W. S. Kiser, J. Urol. Baltimore 90, 594 (1963). - 168. Roberts, A. P.,
J. Frampton, S. M. M. Karim und R. W. Beard, N. England J. Med. 276, 1468 (1967). - 169. Rosalkr, S. B. und J. H. WrikINson, Lancet London 1959/II, 327. - 170. SANTONI, G., R. BeLGERI und C. V. VARIATI, Ann. ostetr. ginec. 87, 795 (1965), Chem. Abstr. 65, 6018 (1966). - 171. Sapira, J. D. und A. P. Shapiro, Amer. J. Med. Sc. 253, 174 (1967). - 172. SASAKI, S. und G. Asboz-Hansen, J. Investigat. Dermat. Baltimore 49, 302 (1967). - 173. Scheler, F. und H. Bergmann, Proc. Europ. Dialysis Transplant. Assoc., 1, 129 (1964). - 174. Schmid, J. D., Invest. Urol. 4, 103 (1966). - 175. SChoenfeld, M. R., J. Amer. Med. Ass. 193, 618 (1965). - 176. Schwartz, M. K. und H. Grabstald, Clin. Chem. (New York) 13, 1092 (1967). - 177. Scotr, J. T., A. M. Denman und J. Dorling, Lancet London

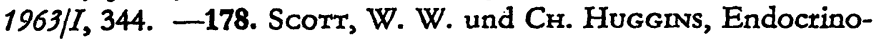
logy 30, 107 (1942). - 179. Sepaha, G. C., C. R. Bhandari und R. Vijayvargiya, Indian J. Med. Res. 49, 68 (1961). - 180. Smyrniotis, E. F., P. A. Fletcher, N. Alkajaersig und S. SHERRY, Thromb. Diath. Haemorrb. (Stuttgart) 3, 257 (1959). 181. Stambaugh, R., A. Goldstein, M. Kopper und D. Post, Proc. Amer. Ass. Cancer Res. 7, 67 (1966). - 182. Szasz, G., P. Baranyar, Zs. Czirbesz und P. Csakr, Klin. Wschr. 43, 783 (1965). - 183. Szasz, G., Zs. Czirbesz, L. Kiraly und P. Csakr, Acta paediatr. Acad. Sc. Hungar. 5, 367 (1964). - 184. Truss, F., Med. Welt 1968, 116. - 185. UNGaR, G., E. DamgaARD und F. P. Hummer, Amer. J. Physiol. 171, 545 (1952). - 186. WACKer, W. E. C., E. Amador, L. E. Dorfman und Th. S. Zrmmerman, Ätztl. Lab. 11, 204 (1965). - 187. WACKER, W. E. C. und L. E. Dorfman, J. Amer. Med. Ass. 181, 972 (1962). - 188. WACKer, W. E. C., L. E. Dorfman und E. Amador, J. Amer. Med. Ass. 188, 671 (1964). - 189. WaTts, C., J. MaC ViCar und D. M. Goldberg, Brit. J. Cancer 20, 282 (1966). - 190. Werssel, W., G. Brechelmacher, H. Hammerl und E. ZimmermanN, Wien Zschr. inn. Med. 45, 73 (1964). - 191. WerLe, E., R. BuSSE und A. Scrirar, Klin. Wschr. 46, 1315 (1968). - 192. West, H. und H. J. Zrmmeraran, J. Laborat. Clin. Med. S. Louis 52, 185 (1958). 193. Wetzels, E. und W. Herms, Dtsch. med. Wschr. 86, 514; 657 (1961). - 194. Wrukinson, J. H., Current Problems Clin. Biochem. 2, H. Huber, Berne 207 (1968). - 195. Wirson, A. T. und W. P. Hadlye, J. Pediatr. S. Louis 36, 199 (1950). - 196. Zurwehma, D., Med. Klin. 61, 1458 (1966). 197. Courtois, J. E., J. F. Demelier, J. Labat und C. Bark: C. R. Soc. Biol. 163, 2092 (1969). - 198. HaendLe, H., H. InGRISCH und E. WerLe, HoppeSeylers Z. physiol. Chem. 351, 545 (1970). - 199. Hultberg, B. and P.A. Ockerman: Clin. Chim. Acta (Amsterdam) 28,169 (1970). - 200. KIpping, D., Z. Haut. Geschl.krkht. 45, 201 (1970. 201. Nustad, K. Brit. J. Pharmacol. 39, 73 (1970). - 202. Petritsch, P., Med. Trib., Osterreich, 2 (14), 3 (1970). - 203. RaAB, W., Path. Microbiol. 36, 73 (1970). - 204. Theiss, W., H. GraefF, U. Bleyd, H. ImMich und W. KuhN, Thromb. Diath. Haemorrh. (Stuttgart) 23, 370 (1970). - 205. SHEHADEH, I. H., C. B. Carpenter, C. H. Monterio and J. P. Merrill: Arch. Int. Med. Chicago 125, 850 (1970).

Univ. Doc. Dr. Wolfgang Raab Währingerstraße 10 A-1090 Wien Osterreich 